\title{
The interaction of large scale and mesoscale environment leading to formation of intense thunderstorms over Kolkata Part I: Doppler radar and satellite observations
}

\author{
P Mukhopadhyay ${ }^{1, *}$, M MahakuR ${ }^{1}$ and H A K Singh ${ }^{2}$ \\ ${ }^{1}$ Forecasting Research Division, Indian Institute of Tropical Meteorology, Dr. Homi Bhabha Road, \\ Pune 411 008, India. \\ ${ }^{2}$ India Meteorological Department, Mausam Bhawan, Lodi Road, New Delhi 110 003, India. \\ *e-mail: mpartha@tropmet.res.in
}

The weather systems that predominantly affect the eastern and northeastern parts of India during the pre-monsoon summer months (March, April and May) are severe thunderstorms, known as Nor'westers. The storms derive their names from the fact that they frequently strike cities and towns in the southern part of West Bengal in the afternoon from the north-west direction while traveling far from its place of genesis over the Bihar plateau. The storms are devastating in nature particularly due to strong (gusty) winds, heavy rains and hails associated with it. Although these storms are well known for its power of causing damages, studies on them are relatively few due to their small size and sparse network of observations. To address this important issue, the evolution of two Nor'westers of 12 March and 22 May 2003 over Kolkata is studied in detail in this paper using hourly Doppler weather radar (DWR) observations and high resolution Meteosat-5 imageries. In addition, supporting meteorological reports are used to find the large scale conditions that influence the moisture convergence and vertical wind shear. The genesis of both the storms is found to be over Bihar-Jharkhand region and beyond the range of the DWR. The satellite observations are found to be useful in identifying the location and initiation of the storms. The movements of the storms are captured by the DWR estimated vertical cross-section of reflectivities. The Doppler estimate shows that the 12 March storm had a vertical extent of about $10-12 \mathrm{~km}$ at the time of maturity and that of 22 May reaching up to $18 \mathrm{~km}$ signifying deep convection associated with these events. The genesis, maturity and dissipation are well brought out by the hourly DWR and satellite imageries. The DWR observations suggest that the systems move at a speed of $20-25 \mathrm{~m} / \mathrm{s}$. The DWR estimated precipitation shows a detailed spatial distribution around Kolkata with several localized zones of heavy rain and this is found to be well supported by the nearby station observations. This study establishes that DWR observations along with hourly satellite imageries are able to capture the evolution of Nor'westers. The study also shows that the composite DWR-satellite information is a reliable tool for nowcasting the location, time and path of movement of Nor'westers. Based on these observations, a conceptual model of the Nor'wester is proposed.

\section{Introduction}

Thunderstorms over eastern and northeastern India are unique in nature particularly due to their severity in terms of strong wind (30-40 kt), heavy rain associated with hail and rapid movement. Most preferred time of appearance are premonsoon months (March, April and May) (Sohoni 1928). These storms cause devastations every year by damaging public life and properties. The loss

Keywords. Thunderstorms; Kolkata; DWR. 

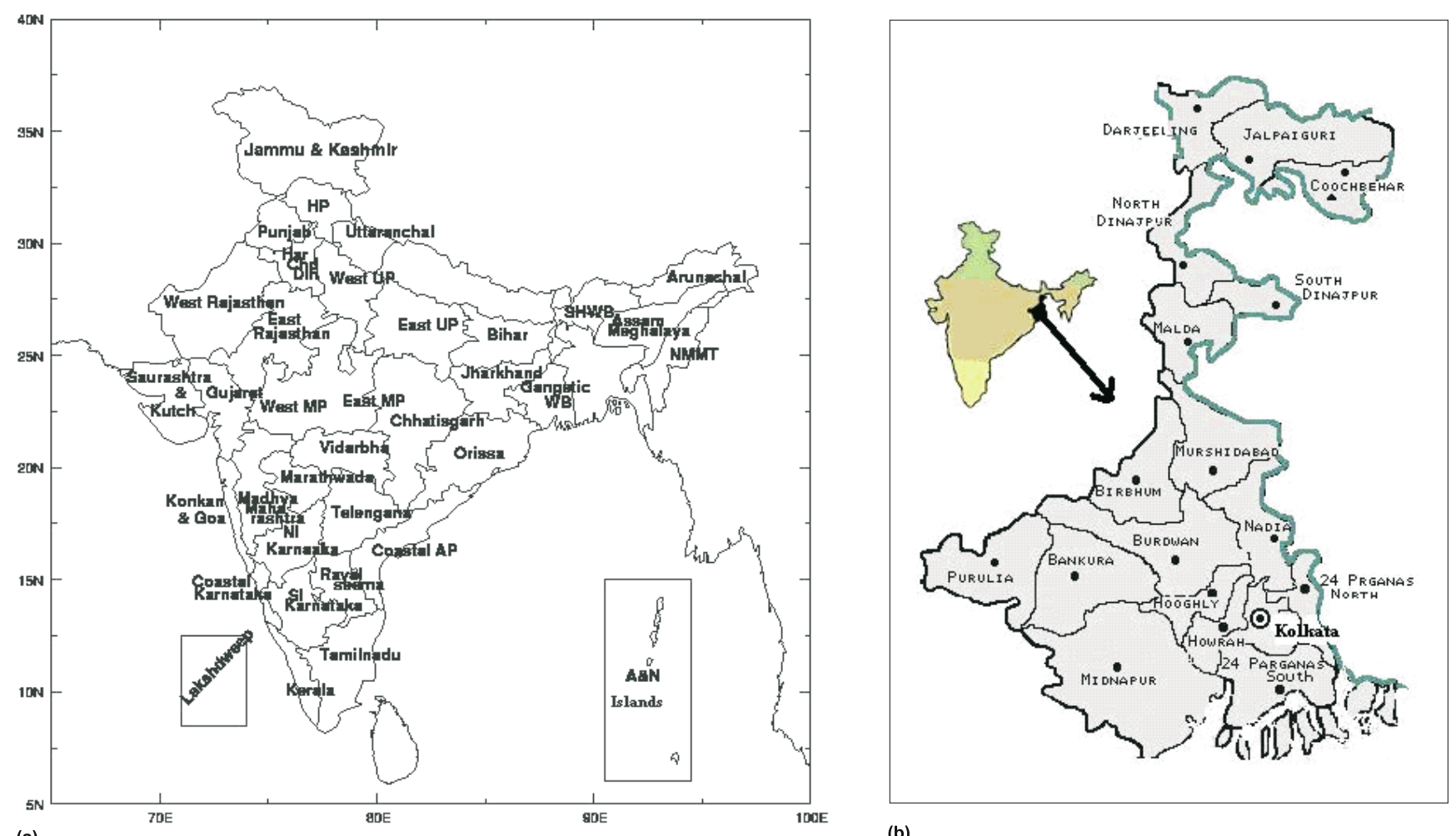

(b)

Figure 1. (a) Indian meteorological subdivisions along with islands of Andaman and Nicobar, and Lakshwadeep; and (b) Map of West Bengal along with the districts.

is particularly caused to the agricultural properties such as mangroves, crops, etc., due to strong winds and hails. Damages are also incurred by the aviation sector, power supply, rail, road and common man. Historically speaking, possibly the first documentation of such a storm was made by Floyd (1838) that struck east of Kolkata on 8 April 1838. He gave a brief explanation about the movement of the storm along with an account of damage by visiting the site after the passage of the storm. The thunderstorms over Gangetic West Bengal are called Nor'westers as these systems having genesis over Bihar, Jharkhand (figure 1a) region travel south-eastward to strike Kolkata (figure 1b) and its surrounding. With respect to Kolkata, these storms appear from the north-west direction hence the name 'Nor'wester'.

A number of studies were carried out in the past on the thunderstorm development and their forecasting utilizing the synoptic observations available over Kolkata and its surrounding regions (Desai 1950; Mull and Rao 1950; Bose 1957; De et al 1957; Rao and Boothalingam 1957; Rai Sircar 1957). Early attempt was made by Das et al (1957) to analyze the movement of Nor'westers of 1955 using a $3 \mathrm{~cm}$ meteorological radar at Dum Dum Airport of Kolkata $\left(22.65^{\circ} \mathrm{N}, 88.45^{\circ} \mathrm{E}\right)$. These studies are based on synoptic data (sparse in spatial and temporal resolution) at different stations and did not elaborate on the mesoscale structure of the systems and particularly their evolution. Thus objective studies addressing the mesoscale structure and evolution of these storms are not attempted. Nor'westers remained one of the least documented severe weather systems of this region.

It is well established by several studies over US (in particular) that Doppler radar has the capability of capturing fast developing convective systems such as thunderstorms and tornadoes. Dostalek et al (2004) analyzed the Weather Surveillance Radar-1988 Doppler (WSR-88D) data and satellite imageries to establish that tornadic thunderstorm developed near the intersection of left moving and south moving boundary. Short et al (2004) documented the life cycle of thunderstorms over Kennedy Space Center and Cape Canaveral Air Force Station using Geostationary Operational Environmental Satellite (GOES)-8 visible imageries and showed the utility of such study in nowcasting thunderstorms. Weaver and Lindsay (2004) utilized the GOES imageries to show the cloud features associated with the different stages of severe/tornadic thunderstorms. They emphasized that high resolution numerical modeling needs to be carried out to simulate the life cycles 
of the clouds associated with severe/tornadic thunderstorms. Kennedy and Detwiler (2003) studied the origin of hail formation from the graupel stage within a multicellular thunderstorm using WSR88D data and aircraft measurement of hydrometeors. Weckwerth (2000) utilized NCAR CP-3 and CP-4 Doppler radar data to find out the strength and depth of horizontal role that triggers thunderstorms on some days and fail to trigger in some other occasions. MacKeen et al (1999) analyzed WSR-88D radar estimated storm height, size and intensity in regard to storm longevity forecasting. Hane et al (1997) have given a detailed explanation of how severe thunderstorms develop along a dry line utilizing data from various platforms such as C-Band and X-band radar, mesonetwork, GOES satellite imageries, etc. He mentioned that the synoptic scale observation hardly gave any insight about the convective initiation which could only be brought out by the observation that can resolve the mesoscale processes. Besides these, thunderstorms evolution and dynamical features are studied using satellite and Doppler radar observations by Wakimoto (1982); Weaver et al (2002); Klimowski and Bunkers (2002) and many others. Studies mentioned above convincingly demonstrate that Doppler radar and satellite observations can bring out mesoscale dynamical feature of the clouds associated with the systems and also the size, intensity and location which otherwise remain unresolved due to inadequate spatio-temporal observation network. Studies on supercell thunderstorms over US mainly address that modest instability and strong baroclinic system are the major large scale factors behind these systems (Gonski et al 1989). It is also proposed that potential vorticity anomaly, jet stream in the upper troposphere and surface frontal wave lead to tornadic thunderstorm outbreak. In a recent article Ricketts et al (2007) mentioned about convective storm initiation project (CSIP) in Hampshire, UK. The primary mechanism of convective initiation as obtained from CSIP was inversion (lid) penetration, lifting of the lid through orography and frontal upglide. Such conclusive relations are yet to be established for Nor'westers.

An objective study towards understanding the role of the large scale near storm environment and the spatio-temporal evolution of the clouds associated with the Nor'westers have not been done over Gangetic Bengal region. A recent paper by Ghosh et al (2008) have addressed some of the lower and middle tropospheric feature in the initiation of Nor'wester. The objective of this paper is therefore to establish the role of large scale environment in the formation and intensification of Nor'westers and the mesoscale structural and dynamical features of the deep convective clouds associated with the systems that occurred on 12 March and 22 May 2003 over Kolkata and surrounding, using hourly Doppler radar observation and Meteosat-5 imageries. Based on the analysis of observations a conceptual model of Nor'wester is proposed for the first time. This study will also be helpful for understanding the underlying processes within the systems and subsequently it may add to the forecasting/nowcasting capability for such mesoscale systems.

The DWR was installed over Kolkata in April 2002. The detailed description and principle of working of the radar was given by Bhatnagar et al (2003). However, some description of the radar features are given in section 2. The 12 March Nor'wester which happened to be the first event of 2003 pre-monsoon season over Kolkata was reported (website of The Telegraph; http://www.telegraphindia.com; website of The Statesman; http://www.thestatesman.net) to have killed 15 people in-and-around Kolkata (adjoining districts) and injured 373 people. In addition, the storm caused widespread damages to power supply, rail, aviation and communication link over this region due to heavy rain associated with hail and strong wind. Kolkata and surrounding was reported (India Meteorological Department (IMD)) to have struck twice by the 12 March Nor'westers with the first one crossing at $09 \mathrm{Z}$ (1430 LT) and the other at $12 \mathrm{Z}$ (1730 LT). The Nor'wester of 22 May, was the last in the premonsoon season of 2003. This storm also caused widespread damage to rail, road, power supply, water logging in the streets of Kolkata and injured hundreds of people. Rainfall of $73 \mathrm{~mm}$ was reported over Kolkata in just 90 minutes by this and the storm was reported to strike Kolkata at $1230 \mathrm{Z}$ (1800 LT).

This paper will be followed by another where the dynamical features of the storms will be simulated using high resolution mesoscale model and verified by the Doppler and Meteosat- 5 imageries.

\section{Brief description of the Doppler radar}

The classifications of radars are done mainly based on the frequency of operation. The Kolkata DWR operates at frequency of $2.875 \mathrm{GHz}$, hence it is an ' $\mathrm{S}$ ' band radar. The radar antenna dish diameter is $8.5 \mathrm{~m}$ and beam width $1^{\circ}$. The peak transmitter power is $750 \mathrm{KW}$. The long and short pulse duration are respectively $2 \mu \mathrm{s}$ and $1 \mu \mathrm{s}$. Pulse repetition frequency is 250 to $1200 \mathrm{~Hz}$. Minimum detectable digital signal is $-110 \mathrm{dBm}$ at low noise amplifier input. To estimate the rainfall rate from the 

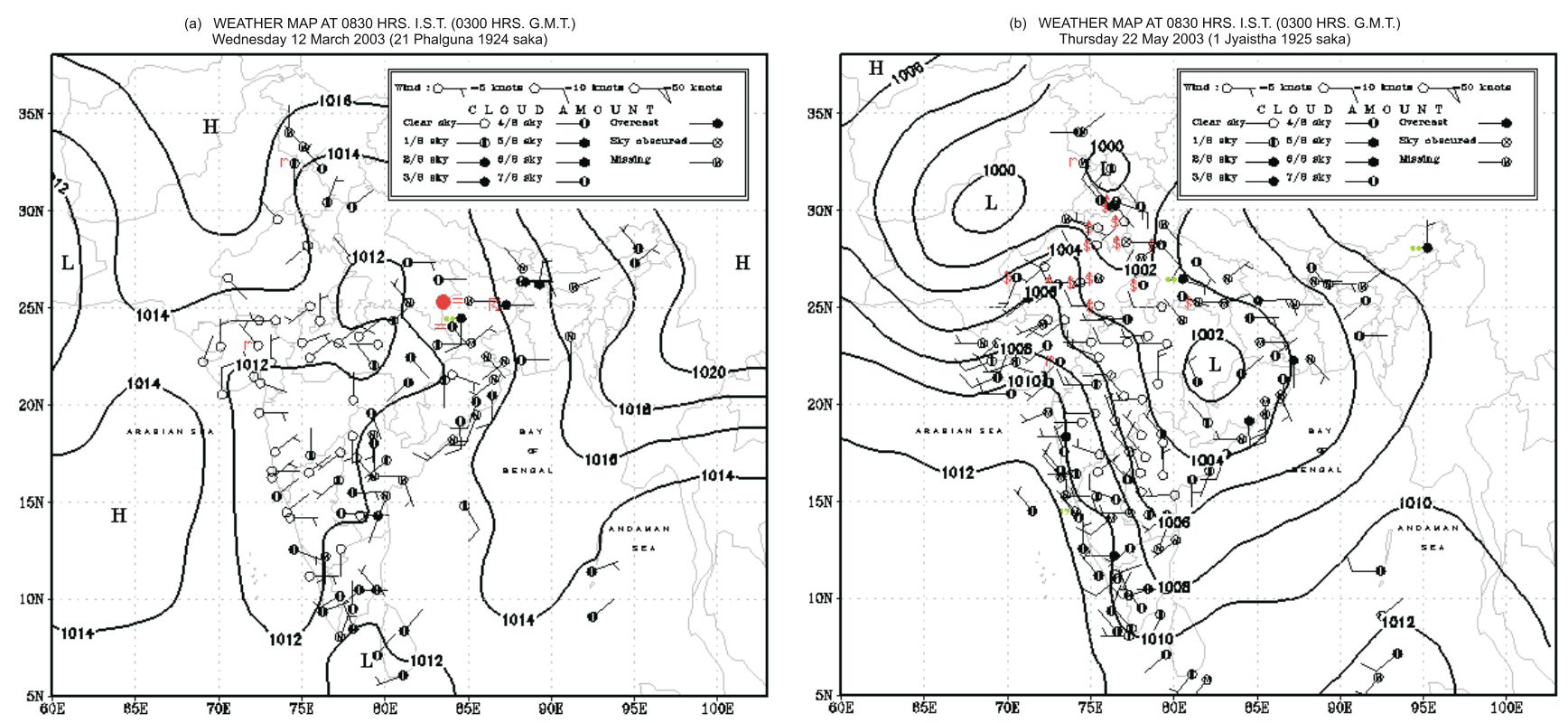

Figure 2. (a) Surface weather map at 03:00 Z of 12 March 2003; and (b) surface weather map at 03:00 Z of 22 May 2003.

radar reflectivity Marshall-Palmer relation is used as follows:

$$
Z=a R^{b}
$$

where $Z=$ radar reflectivity in $\mathrm{dBZ}, R=$ rainfall intensity in $\mathrm{mm} /$ hour, $a=200$ and $b=1.6$.

Vertical integrated liquid (VIL) water content is derived using the following formula:

$$
Z=C M^{D}
$$

where $C=24,000$ and $D=1.82$ are constant for rain derived by Douglas (1964), $M$ is $\mathrm{gm} \mathrm{m}^{-3}$.

\section{Data}

The Doppler radar of Kolkata collected valuable data for the Nor'westers of Gangetic West Bengal during the pre-monsoon months of 2003 at high spatial $(1 \mathrm{~km})$ and temporal resolution (1 hourly). In this paper Doppler radar estimated hourly vertical cross sections of reflectivity, liquid water content, wind velocity, vertical velocity and 12-h accumulated precipitation are analysed. The hourly high resolution satellite imageries in the Visible (VIS), Infra Red (IR) and Water Vapour (WV) bands from the Meteosat-5 satellite (taken from http://www.sat.dundee.ac.uk), are also analyzed. The radiosonde data of 35 stations over Indian region are analysed to show the large scale wind field at lower $(850 \mathrm{hPa})$, middle $(500 \mathrm{hPa})$ and upper $(200 \mathrm{hPa})$ troposphere. 24-h accumulated rainfall reports of IMD and by Climate Prediction Center, NOAA, rain estimate by TRMM and 12-h accumulated rain, estimated by the Doppler radar, are compared to assess the location and spatial distribution of precipitation caused by these two storms in-and-around Kolkata.

\section{Synoptic condition}

Figure 2(a) shows the surface chart plot at $03 \mathrm{Z}$ (0830 LT) of 12 March 2003. A lower level convergence is identified over Bihar and adjoining regions. The surface isobar distributions indicate horizontal pressure gradient towards the Bihar region. Figure 3(a), (b) and (c) shows respectively the streamline at 850,500 and $200 \mathrm{hPa}$ based on radiosonde observations of $00 \mathrm{Z}$ at different IMD observatories over India. A strong convergence is seen (figure 3a) at $1.5 \mathrm{~km}$ (a.s.l.) over Bihar and adjacent region and a troughing is seen at the central Indian region running from East UP $\left(24.0^{\circ} \mathrm{N}\right.$, $\left.80.0^{\circ} \mathrm{E}\right)$ to Karnataka coast $\left(12.0^{\circ} \mathrm{N}, 75.0^{\circ} \mathrm{E}\right)$. The streamline plots show (figure $3 \mathrm{a}$ and $\mathrm{c}$ ) the wind speed at $850 \mathrm{hPa}$ and $200 \mathrm{hPa}$ in and around Kolkata are $20 \mathrm{kt}$ and $115 \mathrm{kt}$ respectively, suggesting a significant vertical wind shear. It is also evident from the $00 \mathrm{Z}$ weather charts that the central and eastern India was under the influence of wind convergence on 12 March 2003. The large scale convergence over land facilitates the moisture convergence which in turn could make the environment more convectively unstable due to enhanced moisture incursions in the lower troposphere from the Bay of Bengal. 
(a) RSRW wind $850 \mathrm{hPa} 00 \mathrm{Z} 12$ MAR 2003

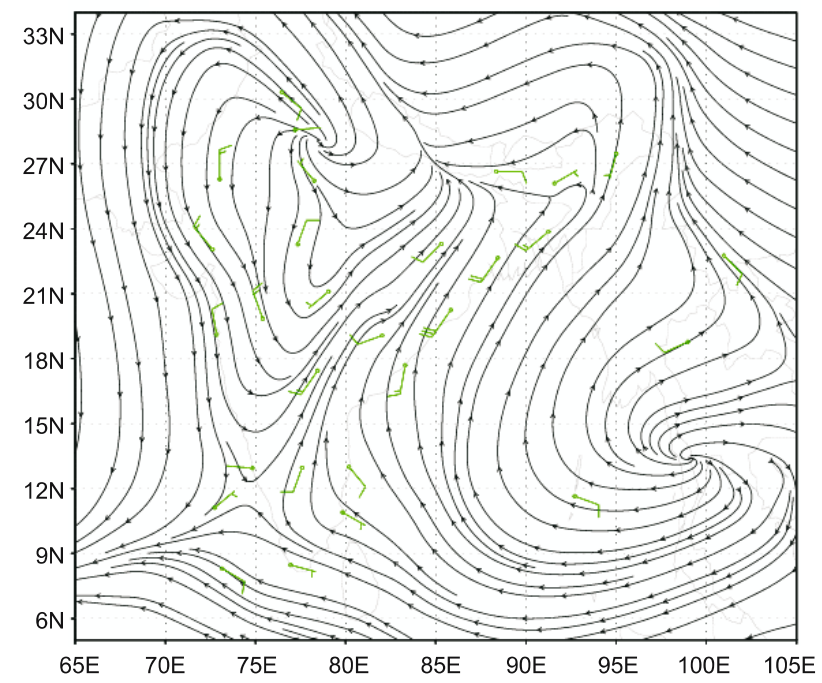

(b) RSRW wind $500 \mathrm{hPa} 00 \mathrm{Z} 12$ MAR 2003

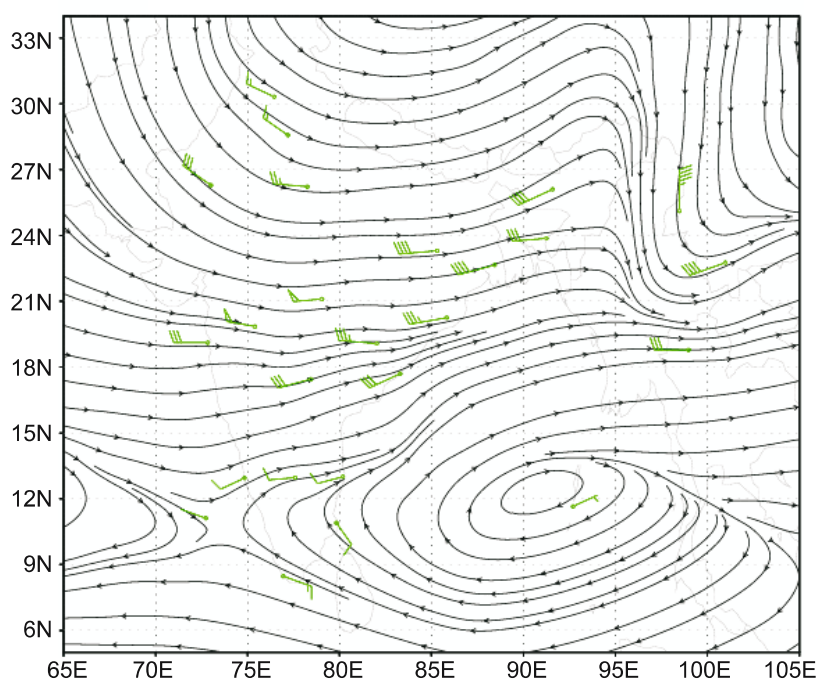

(c) RSRW wind $200 \mathrm{hPa} 00 \mathrm{Z} 12$ MAR 2003

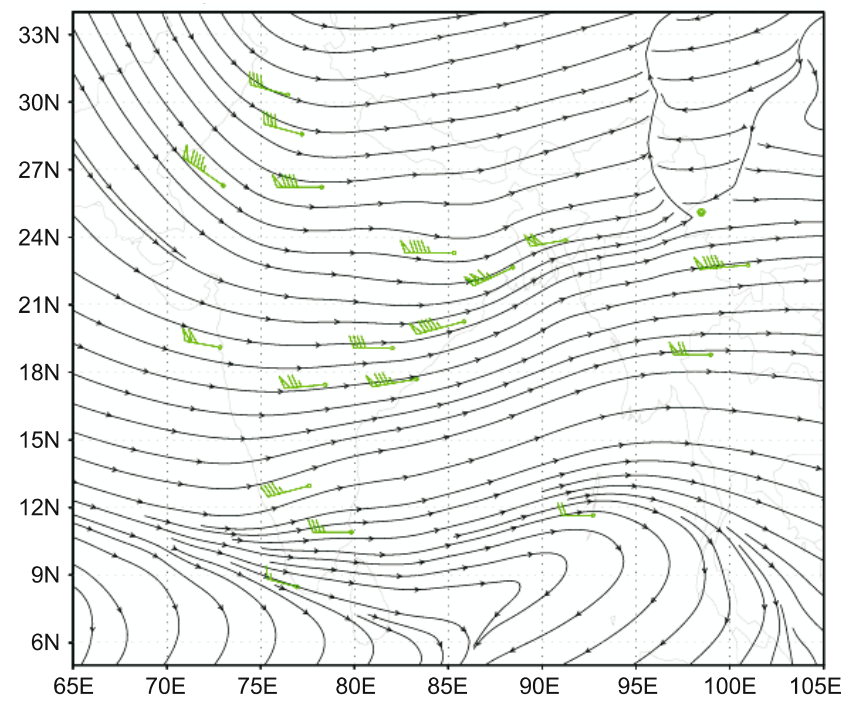

Figure 3. (a) Wind streamline at $850 \mathrm{hPa}$; (b) at $500 \mathrm{hPa}$; and (c) at $200 \mathrm{hPa}$ based on radiosonde (RS/RW) observation at 00:00 Z of 12 March 2003.
Figure 4 shows the surface condition at $09 \mathrm{Z}$ and reveals the gradual change of meteorological parameters from $00 \mathrm{Z}$ to $09 \mathrm{Z}$ around Gangetic Bengal. The surface chart (figure 4) shows wind convergence west of Kolkata over Jharkhand region and formation of a dryline (dotted line) which can be attributed to the mixing of relatively dry air from northwest with warm and moist airmass from Bay of Bengal. The convergence of wind streamline is also seen at $850 \mathrm{hPa}$ and $500 \mathrm{hPa}$ (figure $5 \mathrm{a}$ and b) around $21.0^{\circ} \mathrm{N}, 88.0^{\circ} \mathrm{E}$. The $200 \mathrm{hPa}$ streamline plot (figure 5c) shows a deep trough embedded in the westerlies. The large scale near storm environment has evolved during $00 \mathrm{Z}$ to $12 \mathrm{Z}$ as a more convectively unstable atmosphere. The strong lower level convergence and upper level trough at $12 \mathrm{Z}$ has made the atmosphere conducive for storm generation. The 00 and $12 \mathrm{Z}$ SkewT-Log P plot (based on IMD upper air data at the station) show (figure 9a and b) a significant vertical wind shear which generally indicates the possibility of long lasting squall lines. Figure 2(b) shows the surface plot at $03 \mathrm{Z}$ of 22 May 2003. A low pressure area is identified near Orissa, Jharkhand region. The distribution of isobars indicates substantial pressure gradient over Indian landmass with two low pressure centers located respectively in the extreme northwest India and over Orissa region. The $850 \mathrm{hPa}$ streamline plot (figure 6a) shows a shallow trough passing from Bihar to Tamil Nadu through Jharkhand, Orissa and coastal Andhra Pradesh (A.P.). Comparing the wind fields at three representative levels (figure $6 \mathrm{a}, \mathrm{b}$ and $\mathrm{c}$ ), shear appears to be moderate on $00 \mathrm{Z}$ of 22 May. However, a shallow trough embedded in westerly flow is seen at $850 \mathrm{hPa}(1.5 \mathrm{~km})$. Figure $7 \mathrm{a}, \mathrm{b}$ and c shows a westward vertical tilt of the embedded trough at 12:00 Z. The trough is seen to have moved eastward from 00 to $12 \mathrm{Z}$. These streamline plots of 00 and $12 \mathrm{Z}$ of 22 May 2003 reveal that the region along $85.0^{\circ} \mathrm{E}$ was under the influence of a shallow trough and moderate vertical wind shear. The isobar pattern in the surface chart (figure $2 \mathrm{~b}$ ) around the low pressure area over Orissa and the associated wind field also suggest the existence of the trough. The presence of trough in the lower troposphere facilitates large scale wind and moisture convergence increasing the conditional instability of the atmosphere.

\section{Discussion of results}

\subsection{Nor'wester of 12 March 2003}

As mentioned in section 3, a cyclonic circulation was persisting over Bihar and adjoining region on the early morning of 12 March 2003 (IMD 


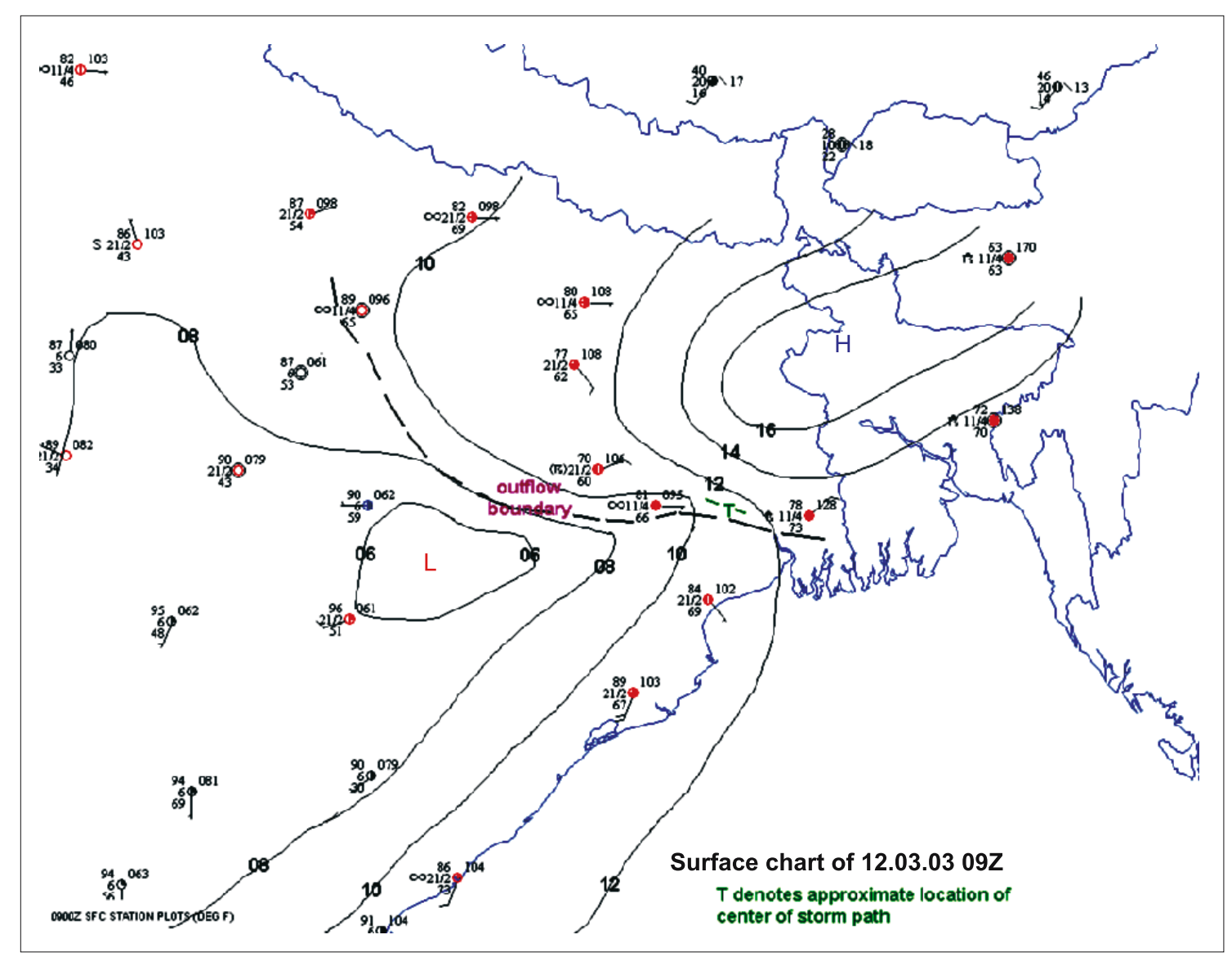

Figure 4. Surface chart of 12 March 2003 09:00 Z.

report). The wind fields in the surface chart at $03 \mathrm{Z}$ (0830 LT) of 12 March 2003 indicate convergence over north of Bihar (red dot in figure $2 \mathrm{a}$ ). The wind discontinuity at $00 \mathrm{Z}$ of $850 \mathrm{hPa}$ level became stronger by $12 \mathrm{Z}$. Strong wind convergence is noticed at $12 \mathrm{Z}$ even up to $500 \mathrm{hPa}$ (figure $5 \mathrm{~b}$ ). Due to the large scale convergence of moist air from south and dry air from the northwest, dry line develops which trigger the initiation of convection. It appears (from the satellite imageries, figure 8) that the convection on 12 March got triggered at around $03 \mathrm{Z}$ and got organized by $09 \mathrm{Z}$. The surface chart (figure 4) shows the outflow boundary which in turn becomes the location of successive cells. The Bihar plateau acts as an elevated heat source and provides additional lifting to the unstable airmass. The morning genesis of the convective system may also be attributed to the low pressure area that was persisting over Bihar and adjoining areas. The lows over land help the air to converge at lower level and make the condition favourable for convection to trigger. The SkewT-Log $\mathrm{P}$ plot at $00 \mathrm{Z}$ over Kolkata shows (figure 9a) high CAPE $(2301 \mathrm{~J} / \mathrm{kg})$ and low CINE $(-13 \mathrm{~J} / \mathrm{kg})$. Other thermodynamic indices such as Total-Total index, $\mathrm{K}$ index, etc., also indicate unstable atmosphere over the station. The strong vertical wind shear between lower $(800 \mathrm{hPa})$ and middle troposphere $(400 \mathrm{hPa})$ is noticed in the sounding plot and duly reflected by the Bulk Richardson Number (BRCH 248.3) which also indicates the possibility of initiation and sustenance of thunderstorms. The level of free convection (LFC) is found to be at $820 \mathrm{hPa}$ and lifting condensation level (LCL) at $970 \mathrm{hPa}$. The thermodynamic structure (figure not shown) of another upper air station Patna $\left(25.60^{\circ} \mathrm{N}, 85.09^{\circ} \mathrm{E}\right)$ in Bihar state, at about $300 \mathrm{~km}$ northwest to Kolkata, also shows highly unstable atmosphere (CAPE$2400 \mathrm{~J} / \mathrm{kg}, \mathrm{TT} \sim 45.0, \mathrm{~K} \sim 24.0, \mathrm{LCL} \sim 965 \mathrm{hPa}$, $\mathrm{LFC} \sim 835 \mathrm{hPa}$ ) at $00 \mathrm{Z}$ of 12 March. The prevailing cyclonic circulation over Bihar appears to have helped in the building up of instability and organization of convection over the region (north of Bihar). Hourly satellite images at 03, 04 and $05 \mathrm{Z}$ (figure 8a, 8b and 8c) show deep convective cloud over Gangetic plains. In the subsequent hours, intense convective cloud gets further organized leading to the formation of an intense system. At $10 \mathrm{Z}$, convective cloud aligns into three distinct cells (shown by black arrows figure 8h). At $11 \mathrm{Z}$ these three cells merged together to make it an intense system. The combined system has moved 
(a) RSRW wind $850 \mathrm{hPa} 12 \mathrm{Z} 12$ March 2003

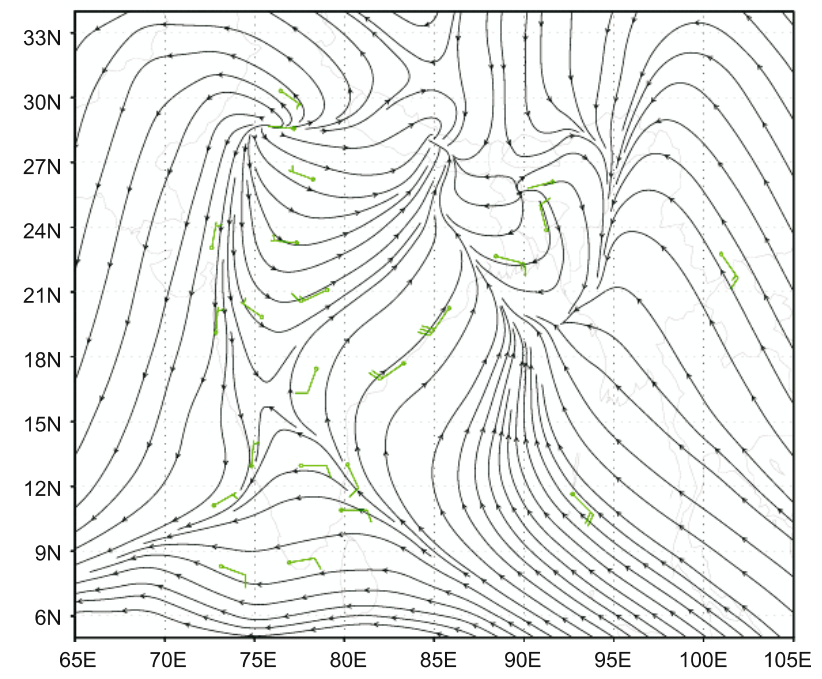

(b) RSRW wind $500 \mathrm{hPa} 12 \mathrm{Z} 12$ March 2003

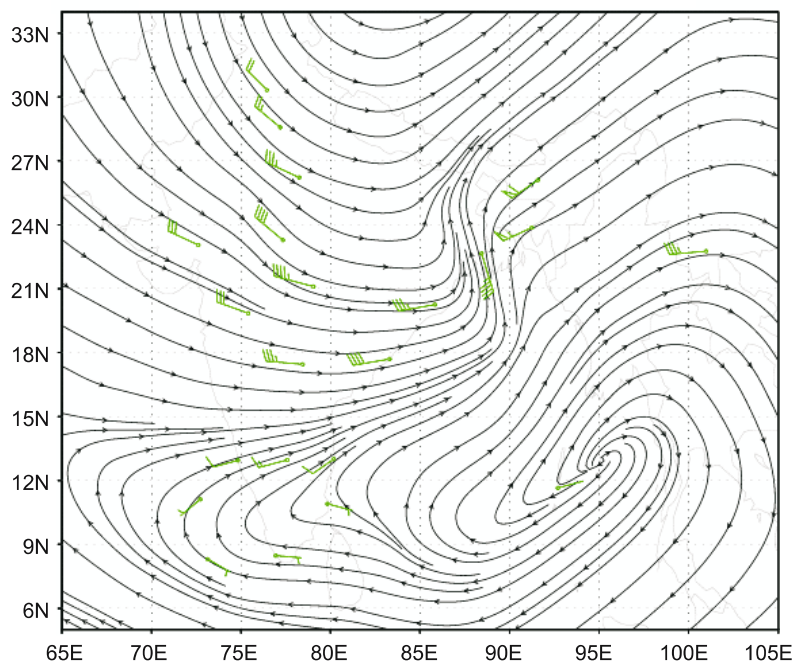

(c) RSRW wind $200 \mathrm{hPa} 12 \mathrm{Z} 12$ March 2003

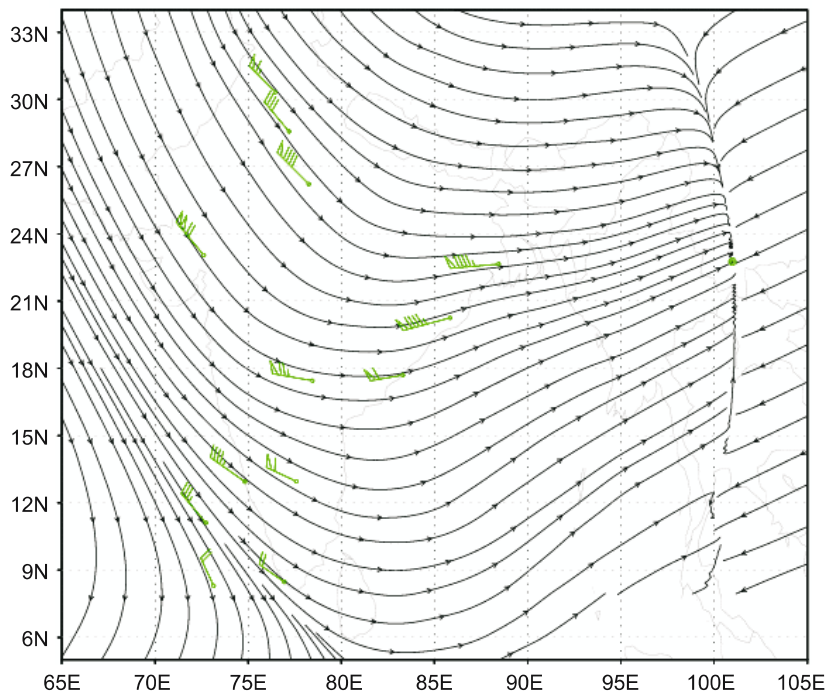

Figure 5. (a) Wind streamline at $850 \mathrm{hPa}$; (b) wind streamline at $500 \mathrm{hPa}$, and (c) wind streamline at $200 \mathrm{hPa}$ based on radiosonde (RS/RW) observation at 12:00 Z 12 March 2003. (a) RSRW wind $850 \mathrm{hPa} 00 \mathrm{Z} 22$ May 2003

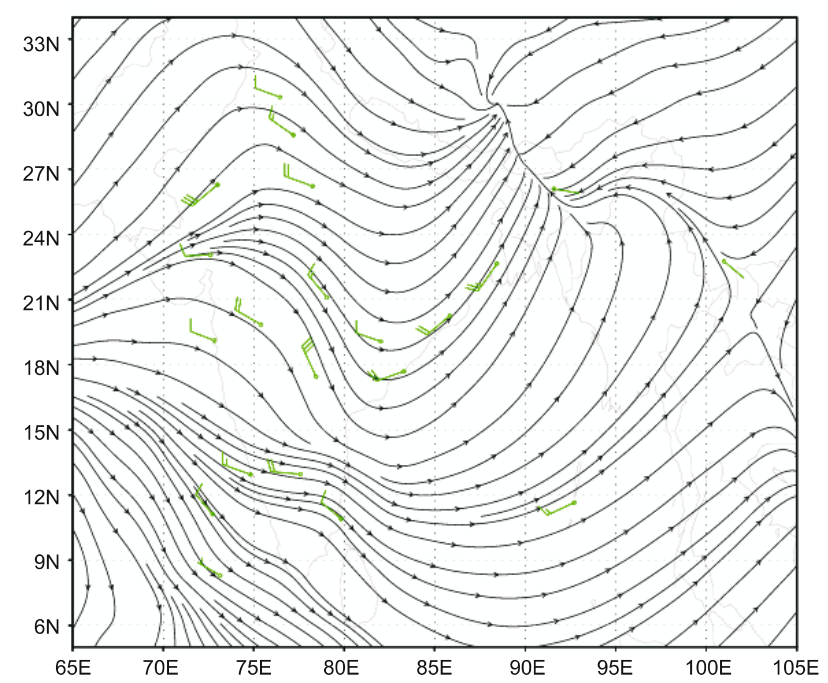

(b) RSRW wind $500 \mathrm{hPa} 00 \mathrm{Z} 22$ May 2003

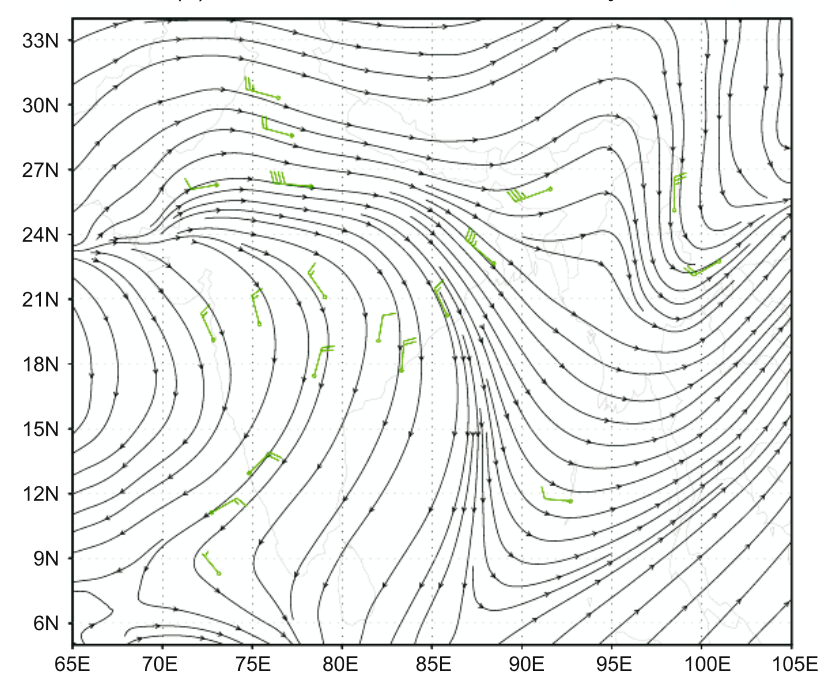

(c) RSRW wind $200 \mathrm{hPa} 00 \mathrm{Z} 22$ May 2003

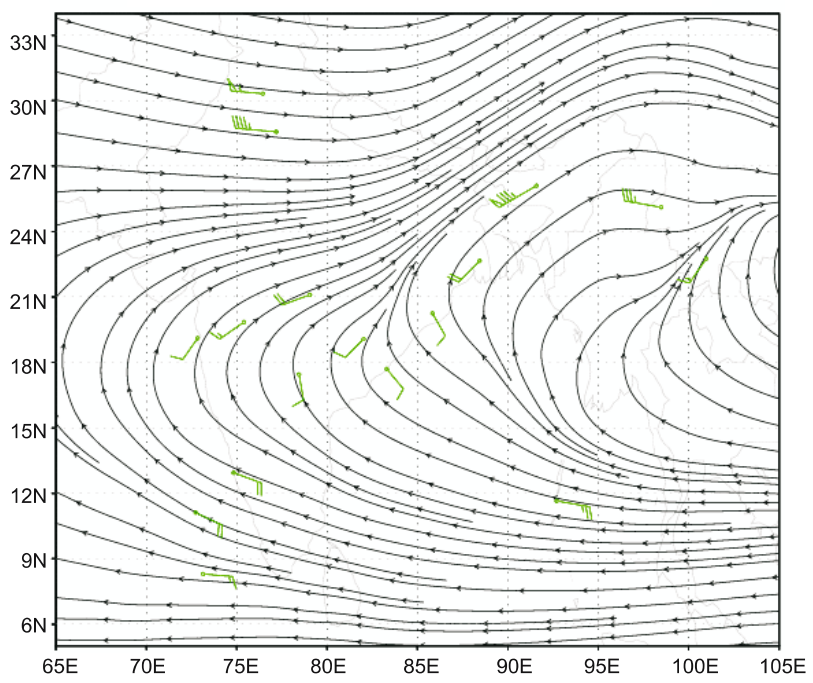

Figure 6. (a) Wind streamline at $850 \mathrm{hPa}$; (b) wind streamline at $500 \mathrm{hPa}$, and (c) wind streamline at $200 \mathrm{hPa}$ based on radiosonde (RS/RW) observation at 00:00 Z 22 May 2003. 
(a) RSRW wind $850 \mathrm{hPa} 12 \mathrm{Z} 22$ May 2003

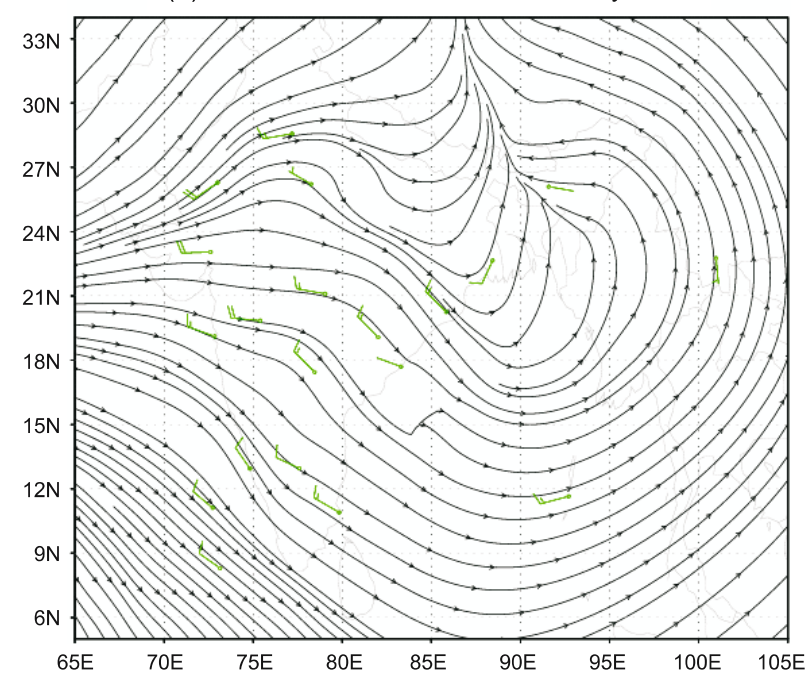

(b) RSRW wind $500 \mathrm{hPa} 12 \mathrm{Z} 22$ May 2003

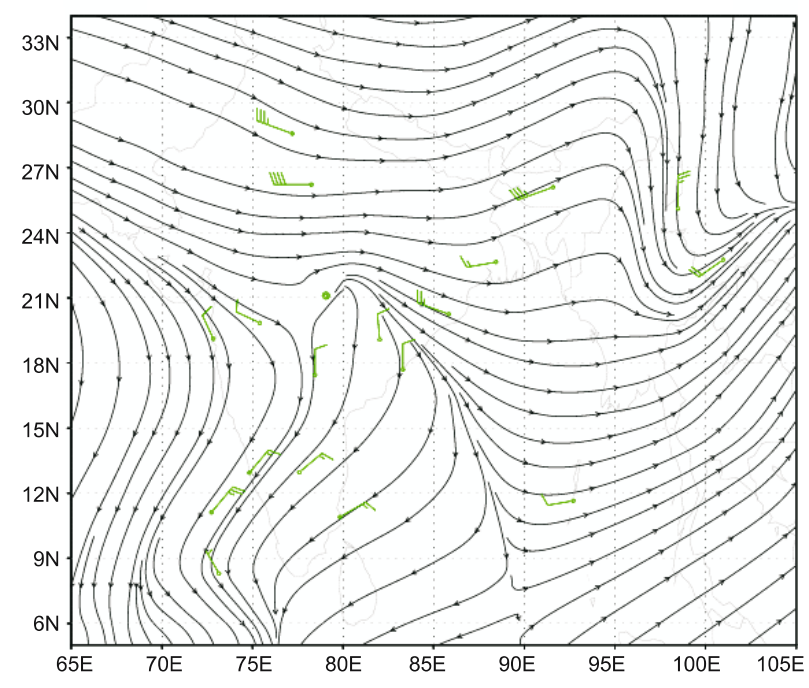

(c) RSRW wind $200 \mathrm{hPa} 12 \mathrm{Z} 22$ May 2003

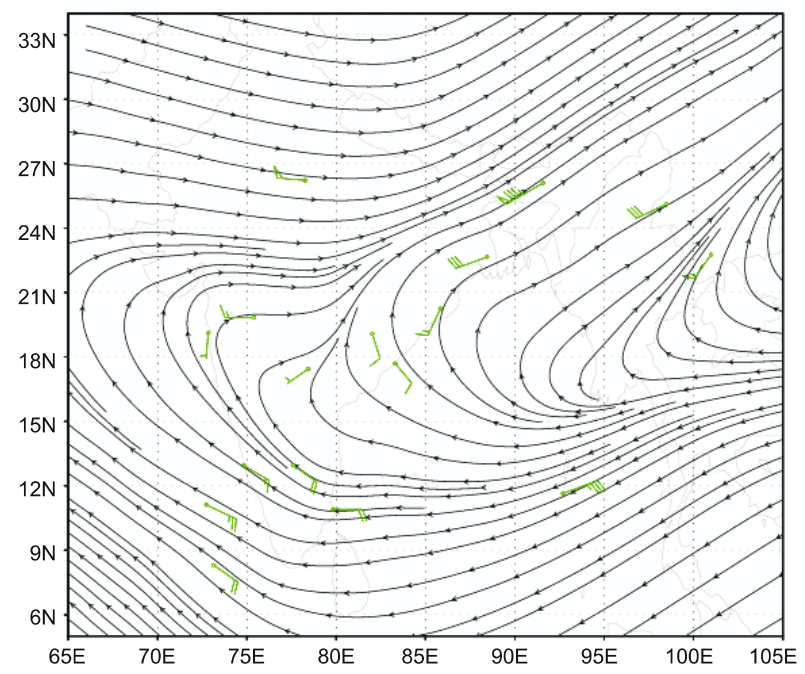

Figure 7. (a) Wind streamline at $850 \mathrm{hPa}$; (b) wind streamline at $500 \mathrm{hPa}$, and (c) wind streamline at $200 \mathrm{hPa}$ based on radiosonde (RS/RW) observation at 12:00 Z 22 May 2003. steadily towards Kolkata. At 12:30 Z another system appeared to the northwest of the previous one (black arrow figure $8 \mathrm{j}$ ) and is seen to move southeastward during the following hours. The $12 \mathrm{Z}$ SkewT-Log P plot of Kolkata shows (figure 9b) significant reduction of CAPE $(384 \mathrm{~J} / \mathrm{kg})$ which indicates release of energy over the station with the passage of the storm and water loading due to rain. LCL and LFC are found to be at lower levels (985 and $969 \mathrm{hPa}$ respectively) suggesting an almost saturated atmosphere. The relative humidity curve (figure 9b) shows 100\% saturation till the $600 \mathrm{hPa}$ signifying high convective instability over the station.

The vertical cross section of east-west and northsouth component of Doppler radar reflectivities are shown in figure 10. At 08:48 Z (figure 10a), a system is detected $150 \mathrm{~km}$ north-west to Kolkata. The vertical extent of the system is found to reach $12 \mathrm{~km}$. This system steadily moved eastward as seen in the Doppler radar observations in figure 10(b, c). During 09:48-10:48 Z two more systems approached Kolkata from the north-west. These are denoted as 2 and 3 in figure 10(c). The second system (shown as 2 in figure 10c) was located $150 \mathrm{~km}$ west of Kolkata and the third system (3) was at $250 \mathrm{~km}$ north-west of Kolkata at 10:48 Z and the first system (1) by this time was nearby to Kolkata. The vertical extent of the system (1) is found to exceed $14 \mathrm{~km}$ whereas that of 2 and 3 is seen to be around 14 and $12 \mathrm{~km}$ respectively at $10: 48 \mathrm{Z}$. The alignment of these three systems at 10:48 Z as captured by the DWR is supported by the satellite observations at $11 \mathrm{Z}$ (figure $8 \mathrm{~h}$ ). The consecutive strike by the three Nor'wester cells have made the event of 12 March severe for Kolkata and surrounding region in terms of devastations. As such this storm has been specially mentioned as an extreme event of Gangetic West Bengal in the NCDC, NOAA climate monitoring site (http://www.ncdc.noaa.gov/oa/climate/research/ 2003). The first system (1) is seen to move eastward and cross Indo-Bangladesh border with high intensity (vertical height $14 \mathrm{~km}$ ) by $11: 48 \mathrm{Z}$ whereas the other two systems (2 and 3 ) moved right and steadily approached Kolkata to strike the city at 13:48 Z (figure 10f). In the subsequent hours these systems slowly dissipated south of Kolkata towards Bay of Bengal. The time evolution of height of convective cloud derived from Doppler observations for system ' 1 ' and ' 2 ' are plotted respectively in figure 11(a) and (b). The system ' 1 ' approached Kolkata with towering cloud of height $14 \mathrm{~km}$ at its full maturity whereas system ' 2 ' reached Kolkata at the time of dissipation with a height of cloud extending up to $10 \mathrm{~km}$. Apart from the different stages, DWR derived vertically integrated liquid water content (LWC) (figure 12) 
(a) $03 \mathrm{Z} \mathrm{IR}$

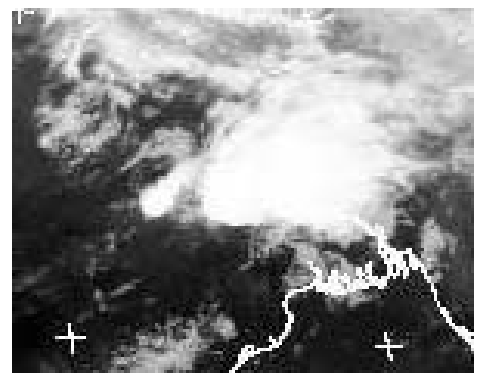

(b) 04 Z IR

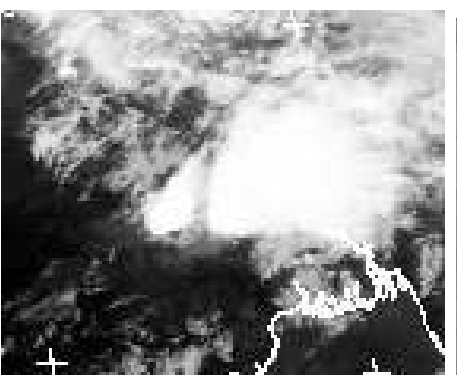

(e) 07 Z IR
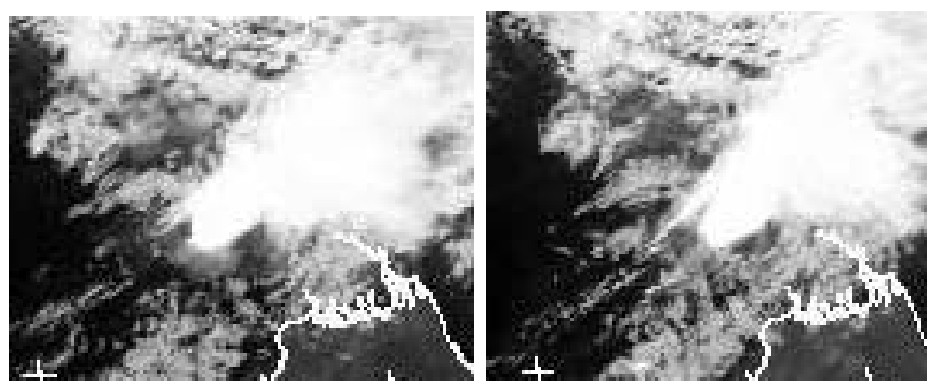

(h) 10 Z VIS
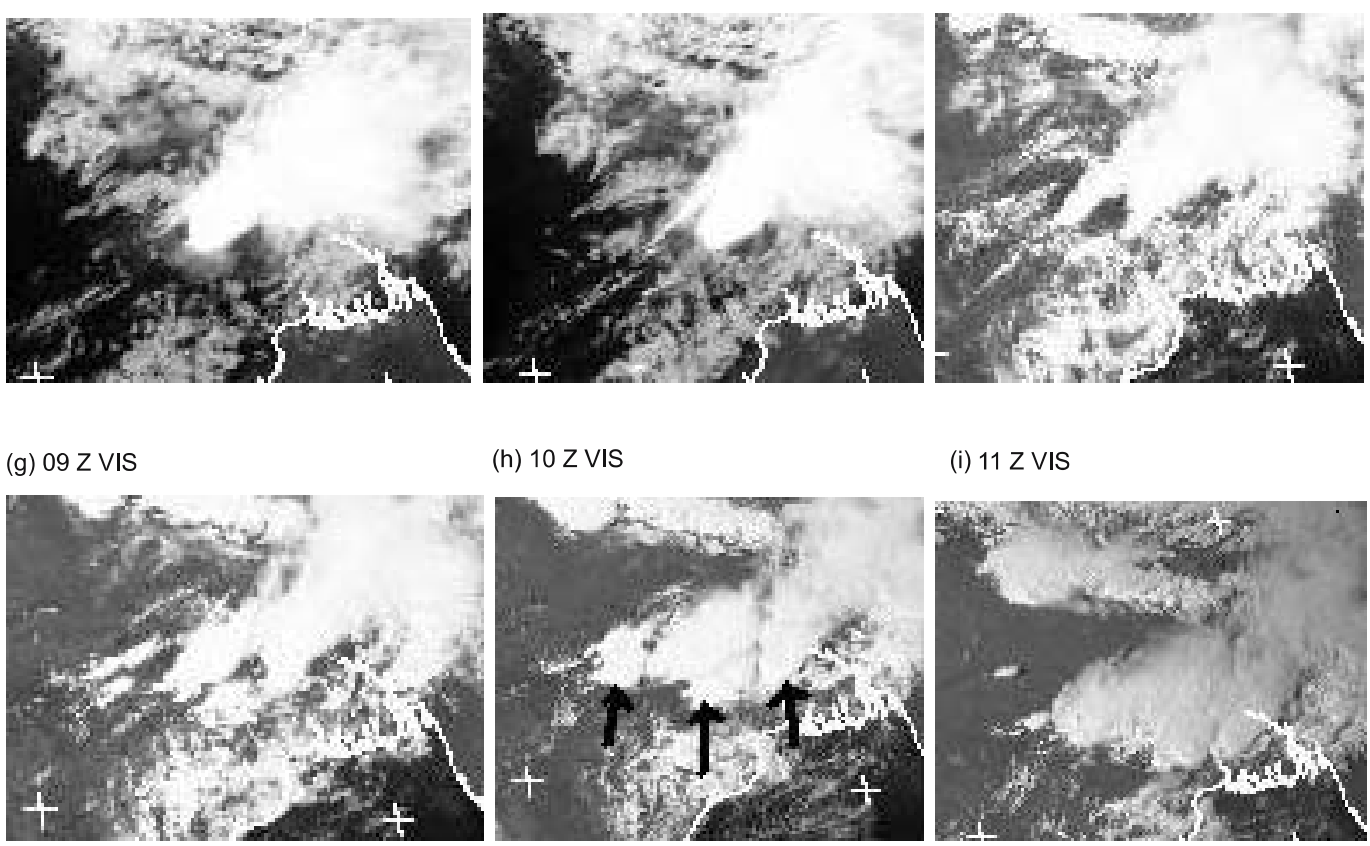

(i) $11 \mathrm{Z} \mathrm{VIS}$

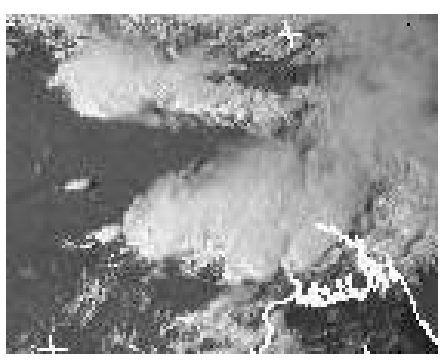

(j) $1230 \mathrm{Z} \mathrm{WV}$

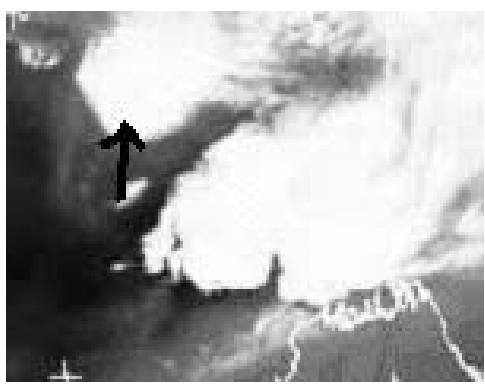

(k) $13 Z \mathrm{IR}$

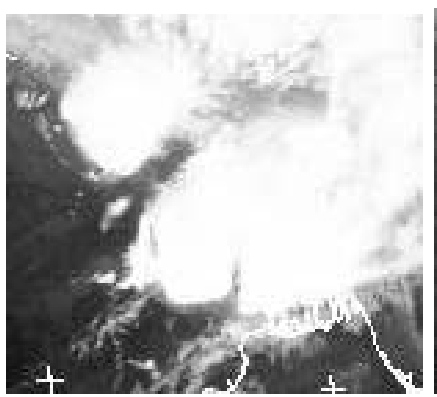

(I) $14 \mathrm{Z} \mathrm{IR}$

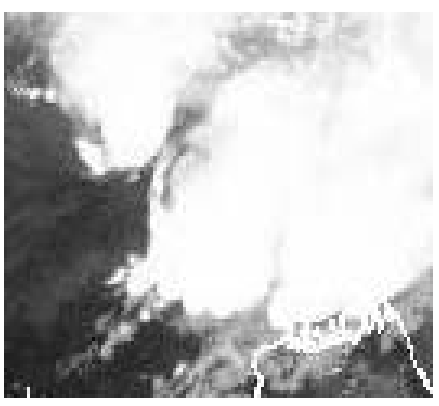

(o) 16 Z IR

(m) $1430 \mathrm{ZWV}$

(n) $15 \mathrm{Z} \mathrm{IR}$
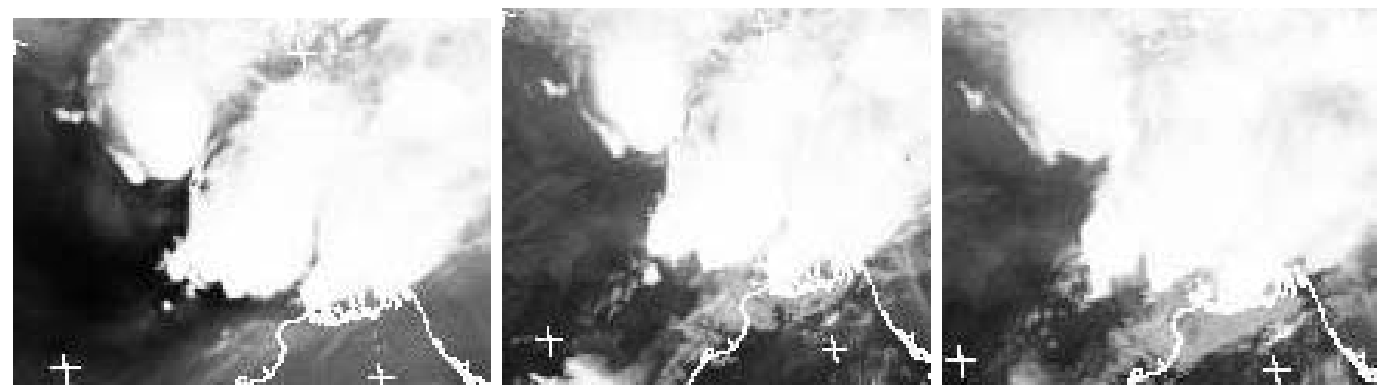

(c) $05 \mathrm{Z} \mathrm{VIS}$

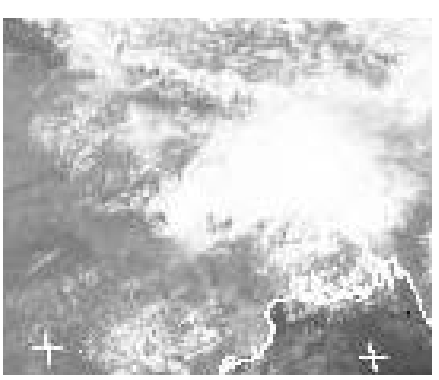

(f) $08 \mathrm{Z} \mathrm{VIS}$ 
signifies the potential rain bearing cloud and possibility of heavy precipitation associated with the system. The three systems aligned one after another as noticed in the satellite image of 10:00 Z (figure $8 \mathrm{~h}$ ) and the radar reflectivities at 10:48 Z (figure 10c), are also found in LWC at 10:48, 11:18 and 11:48 $\mathrm{Z}$ (figure 12e, $\mathrm{f}$ and $\mathrm{g}$ ). These suggest that the first system (1) after approaching towards Kolkata with increased intensity during 08:48 to 09:48 Z (figure 12a-12c), weakened a bit during $10: 48$ to $11: 18 \mathrm{Z}$ (figure $12 \mathrm{e}$ and $12 \mathrm{f}$ ) and regained intensity during $11: 48$ to $12: 48 \mathrm{Z}$ (figure $12 \mathrm{~g}-12 \mathrm{i}$ ) and move further east toward Bangladesh. The second (denoted as ' 2 ') and third systems (denoted as ' 3 ') moved south-eastward and weakened south of Kolkata (figure 12h-k). The systems ' 2 ' and ' 3 ' thus appear to be right moving super cells. The movement of the systems has been influenced by the upper level westerlies. It may be noted here that the strong system that is detected by the satellite observations at 12:30 Z (black arrow in figure $8 \mathrm{j}$ ) is not captured by the DWR in figures 10 and 12 which could possibly be due to the system being at a distance of more than $300 \mathrm{~km}$ from Kolkata and beyond the range of the radar. As such, due to this, the composite of satellite and DWR could give better guidance for nowcasting and tracking of the Nor'westers.

The 24-h accumulated precipitation estimate valid at $00 \mathrm{Z}$ of a day from National Weather Service's Climate Prediction Centre (CPC) over South Asian region including India and the DWR derived 12-h accumulated precipitation $(\mathrm{mm})$ is compared to assess the location and amount of rain caused by the event. The CPC precipitation estimate is based on the GTS information of daily

(a) 12 March $200300 Z$

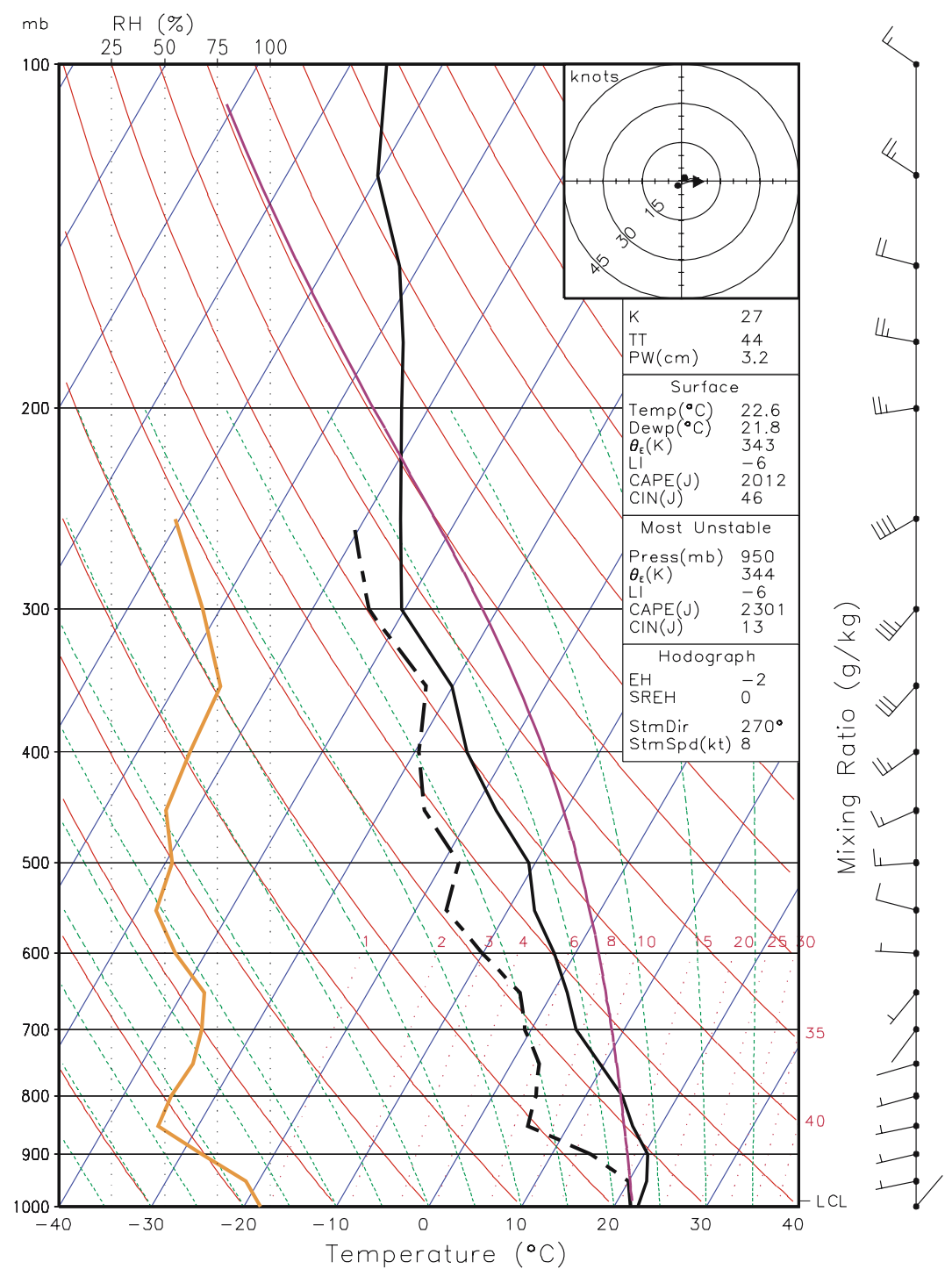

Figure 9. SkewT-Log P plot of Kolkata station (a) at 00:00 Z; and (b) $1200 \mathrm{Z}$ of 12 March 2003. 
(b) 12 March $200312 Z$

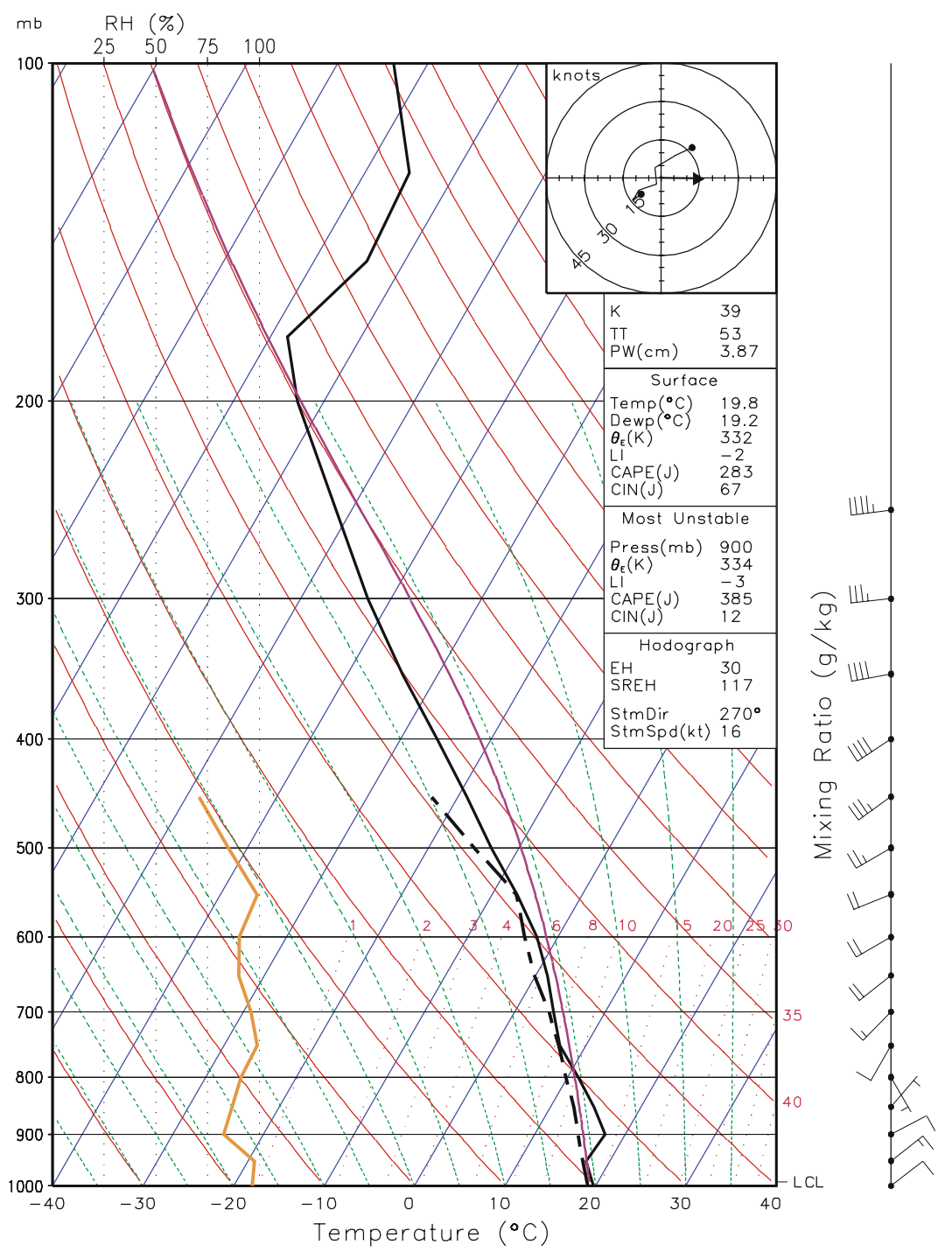

Figure 9. (Continued).

station rain gauge reports, Special Sensor Microwave Imageries (SSMI) estimate, Advanced Microwave Sounding Unit (AMSU) estimate and GPI cloud-top IR temperature precipitation estimate. The precipitation estimate of CPC (figure 13a) suggests heavy rainfall of the order of $100 \mathrm{~mm}$ around Kolkata. However, a very detailed spatial distribution of precipitation pattern is found in the DWR observation (figure 13b). The precipitation distribution clearly suggests the path of movement of the storm. Some pockets around $50 \mathrm{~km}$ north of Kolkata is found to receive $100 \mathrm{~mm}$ of rain (shown as dotted line and name 'A' figure 13b). An IMD rain gauge station Krishnanagar (WMO Stn Index 42711, $88.52^{\circ} \mathrm{E}, 23.40^{\circ} \mathrm{N}$ ) around $50 \mathrm{~km}$ north of Kolkata reported $30 \mathrm{~mm}$ rain on 12 March which further supplements the DWR estimate. Another pocket around $40-50 \mathrm{~km}$ south-west of Kolkata is captured in DWR observation that received $10 \mathrm{~mm}$ of rain (shown with thin arrow named as ' $C$ ' in figure 13b). IMD raingauge station Midnapore (WMO Stn. index $42803,87.32^{\circ} \mathrm{E}, 22.42^{\circ} \mathrm{N}$ ) reported $30 \mathrm{~mm}$ rain on 12 March. DWR rain estimate suggests a wide region south of Kolkata near Bay of Bengal to receive $100 \mathrm{~mm}$ rain during 11 hour (thick arrow and named ' $\mathrm{B}$ ' figure 13b), this may possibly be attributed to the fact that the systems (2 and 3) have moved south-eastward and dissipated over this region. The IMD station at Dum Dum $\left(22.65^{\circ} \mathrm{N}, 88.45^{\circ} \mathrm{E}\right)$ Airport of Kolkata reported $50 \mathrm{~mm}$ of rain. All the reports of IMD station rain gauge appear to be supporting figure 13(b). Infact the DWR estimated rainfall is able to show detailed spatial distribution around Kolkata which is not possible to be achieved unless 
(a) $08: 48 \mathrm{Z}$

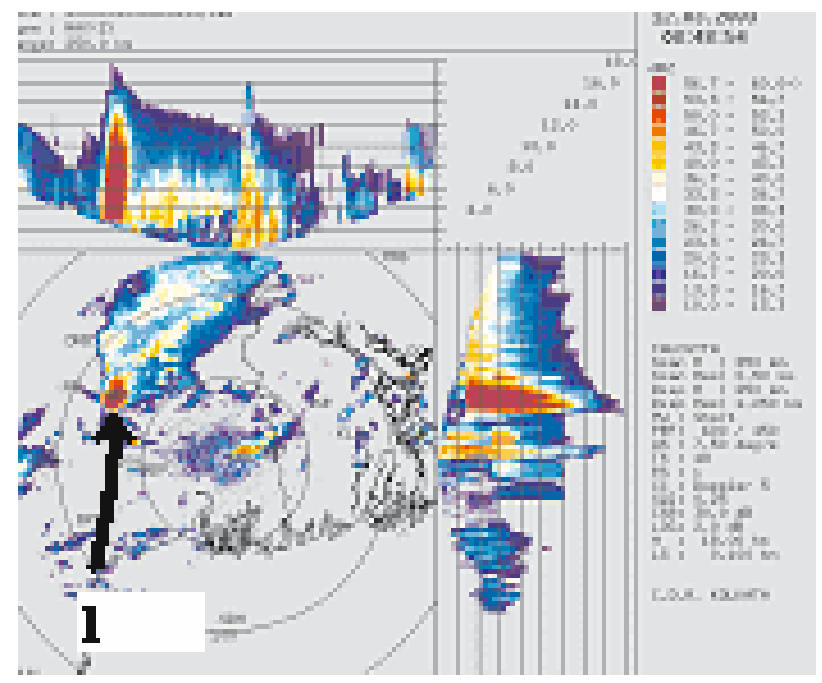

(b) 09:48 Z

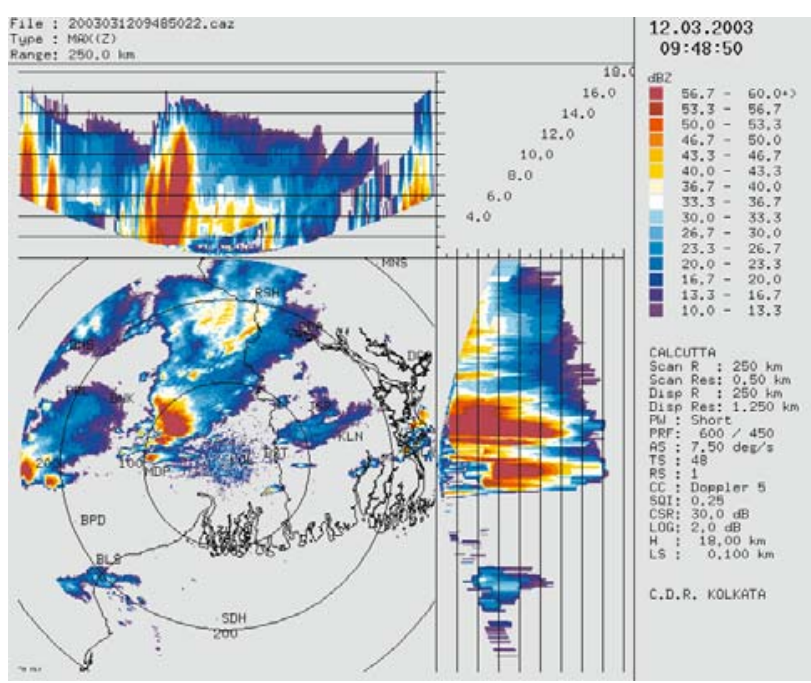

(c) $10: 48 \mathrm{Z}$

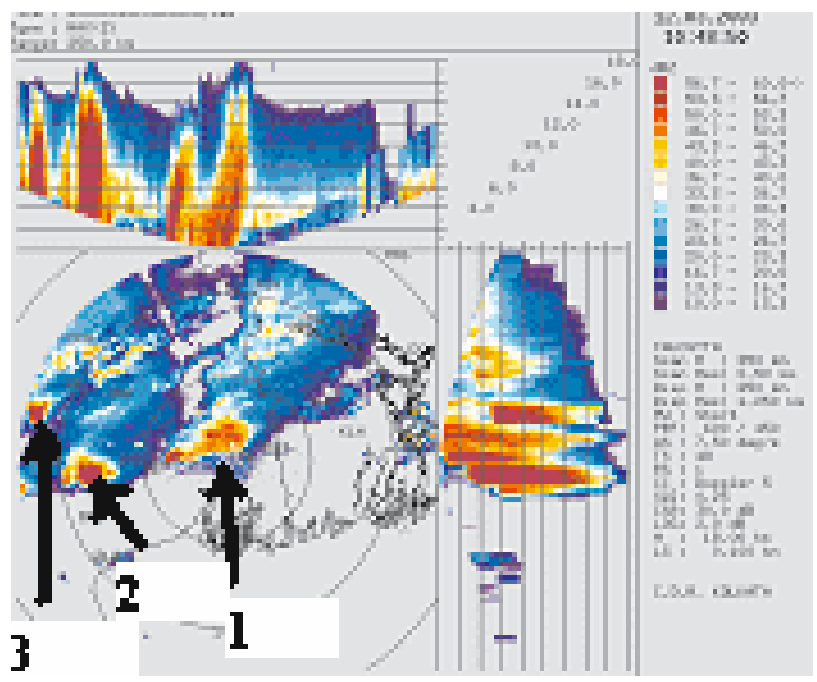

(d) $11: 48 \mathrm{Z}$

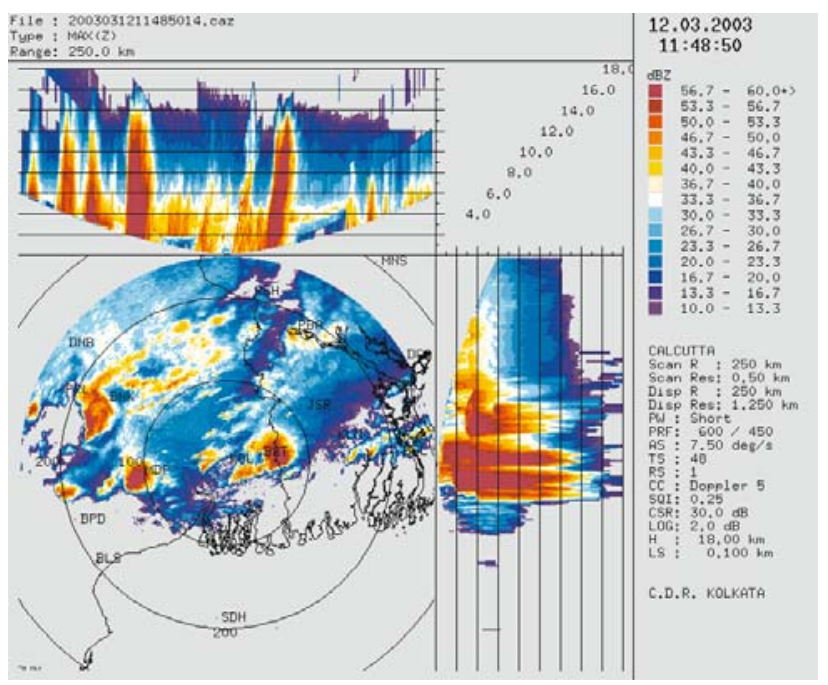

(f) $13: 48 \mathrm{Z}$

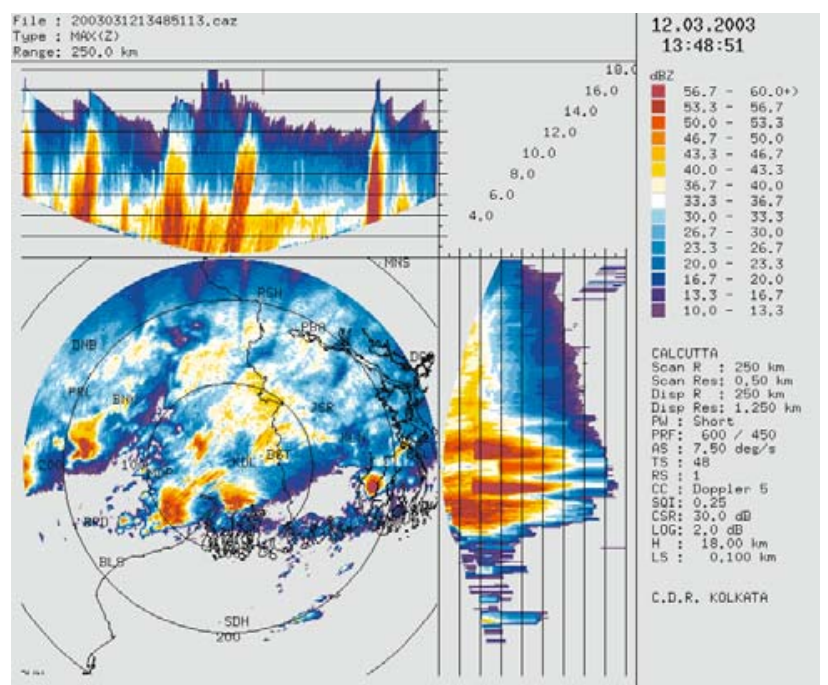

(e) $12: 48 \mathrm{Z}$

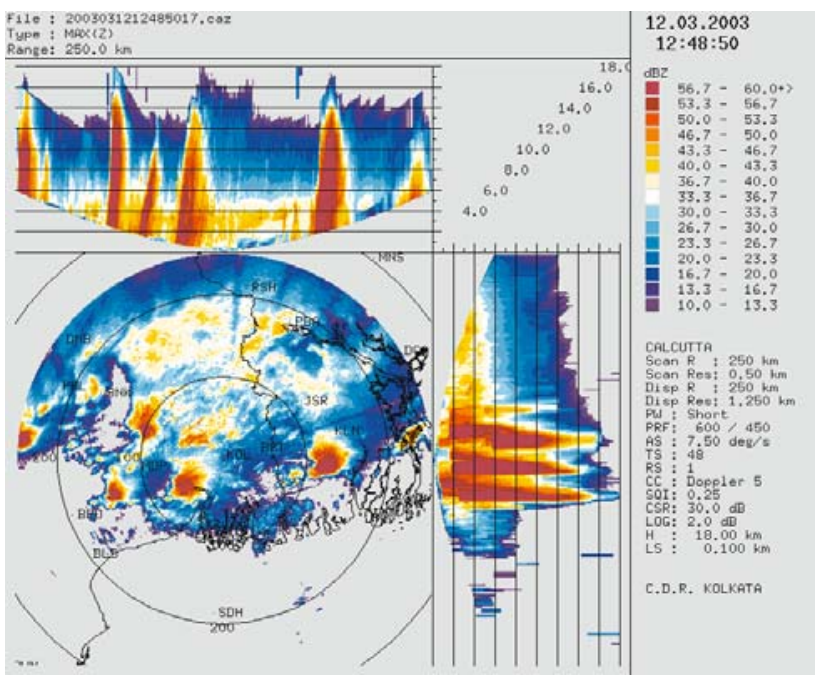

Figure 10. Hourly cross-section $(\mathrm{x}-\mathrm{z}, \mathrm{y}-\mathrm{z})$ of Doppler radar reflectivities of 12 March 2003 Nor'wester. 
(g) $14: 48 \mathrm{Z}$

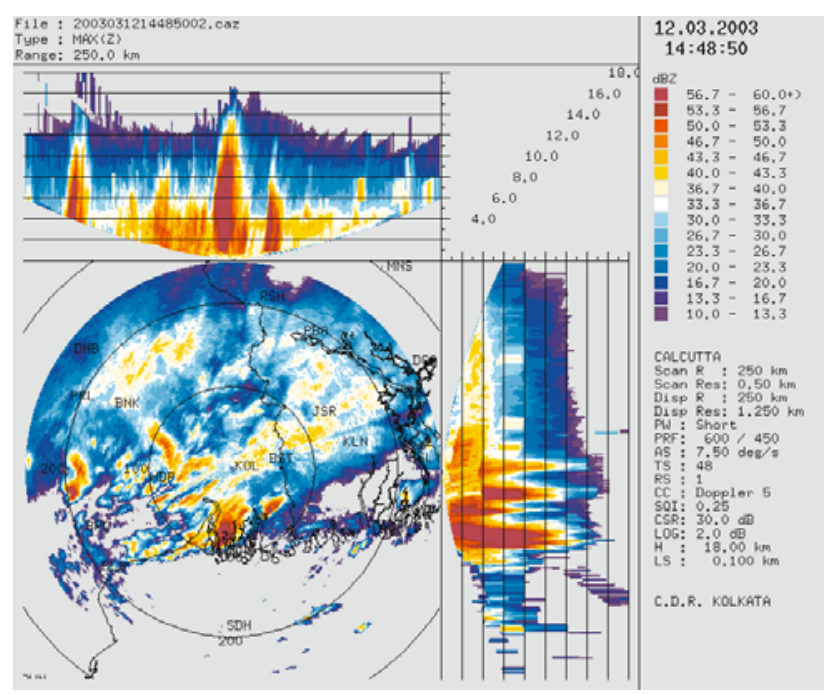

(i) $16: 48 \mathrm{Z}$

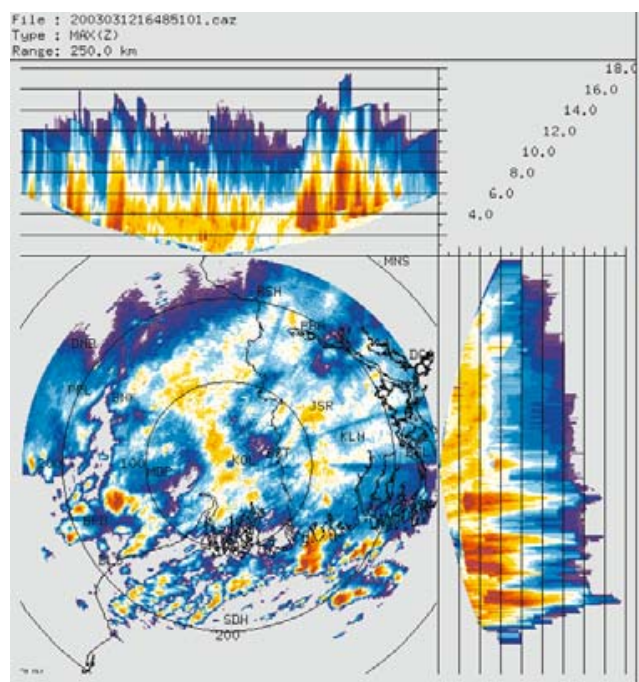

(h) $15: 48 Z$

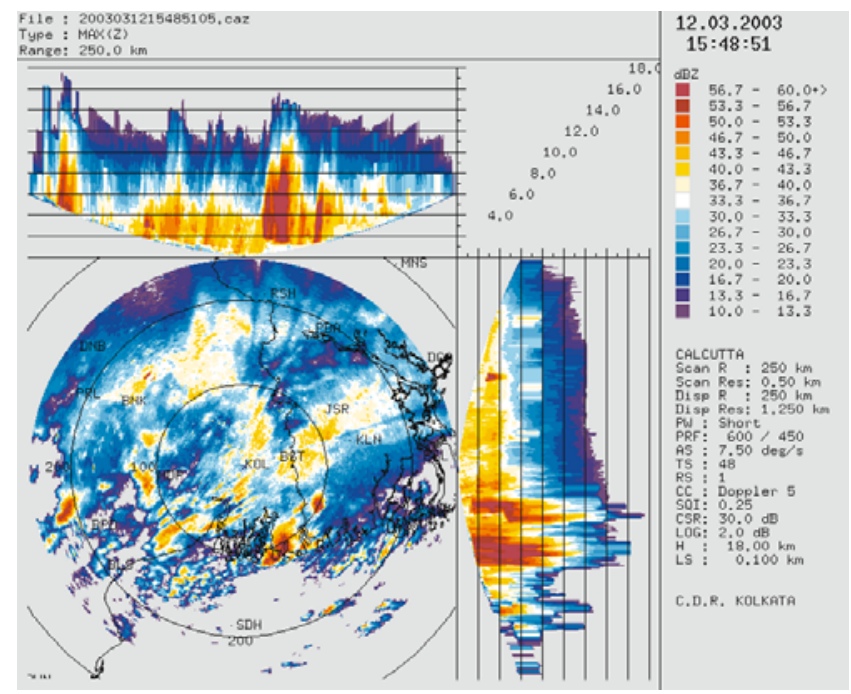

\section{(j) $17: 48 \mathrm{Z}$}

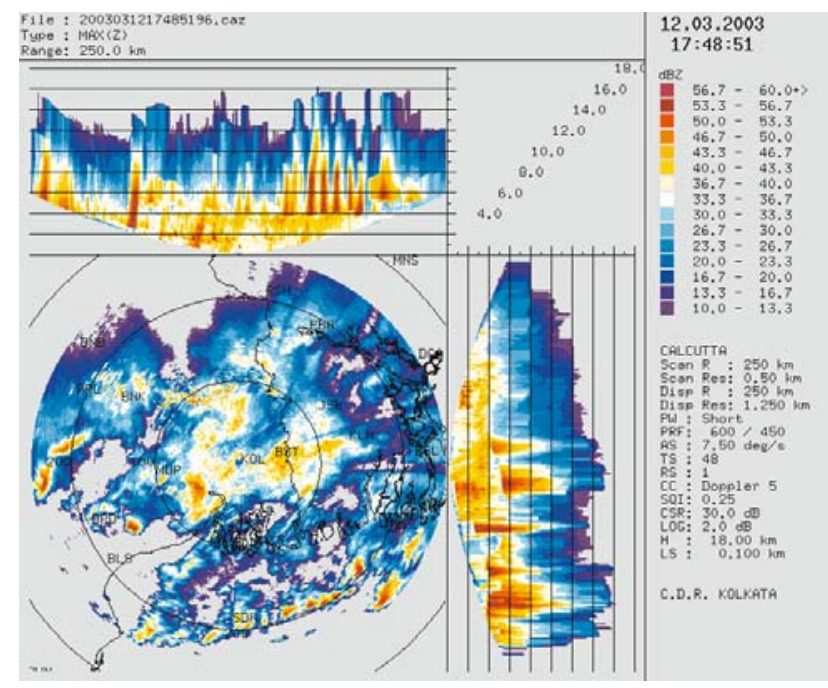

(k) $18: 48 \mathrm{Z}$

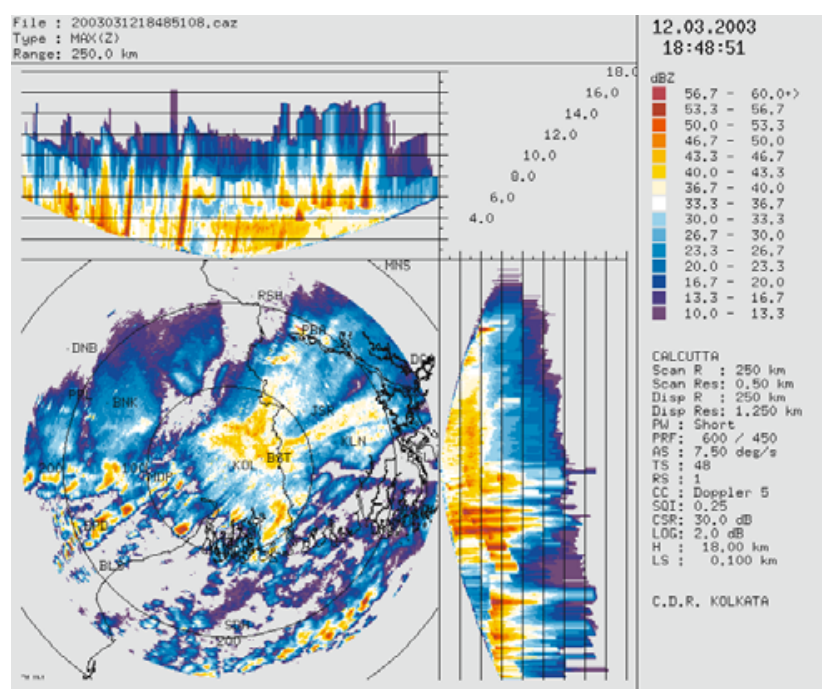

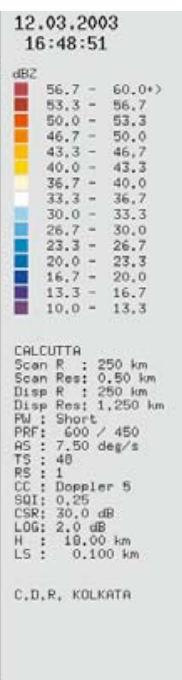

Figure 10. (Continued) 


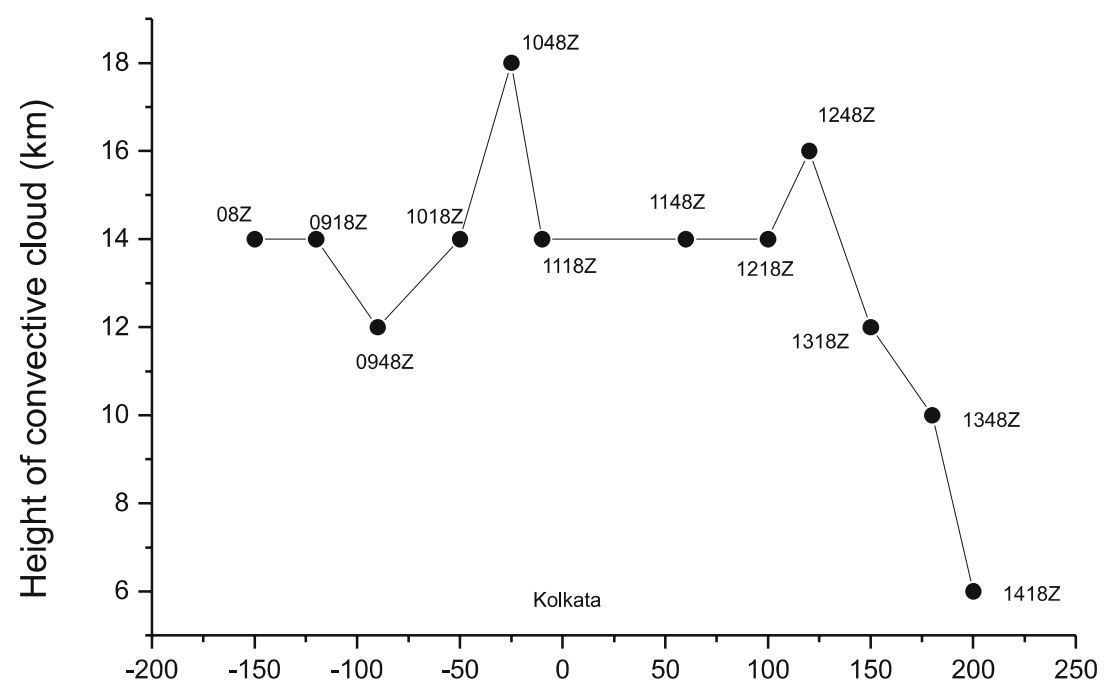

(a)

Distance $(\mathrm{km})$ of the system ' 1 ' from Kolkata

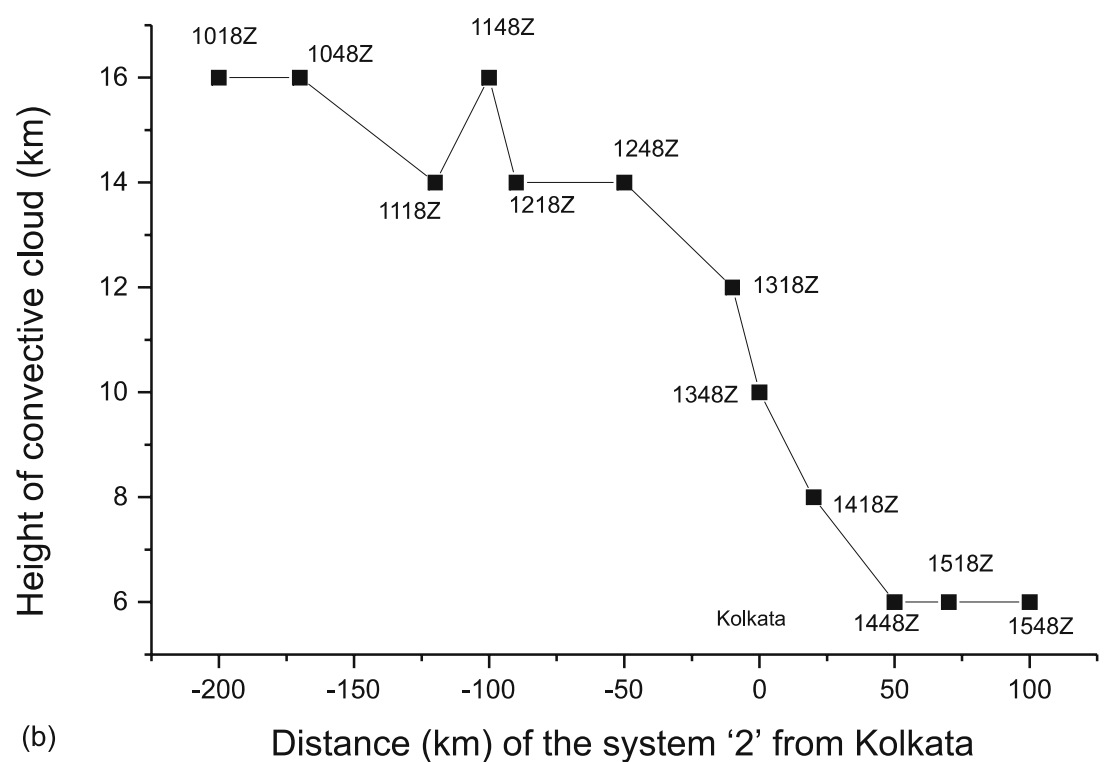

Figure 11. (a) Height of convective cloud associated with system '1' and (b) that of system '2' and distance from Kolkata station at different hour.

rain gauges are physically installed at high spatial density.

\subsection{Nor'wester of 22 May 2003}

The Nor'wester of 22 May was the last of the premonsoon season to strike Kolkata city. Figure 6 shows the large scale lower and upper tropospheric wind field and streamlines over Indian region at $00 \mathrm{Z}$. Figure 7 shows the same at $12 \mathrm{Z}$. Both these figures establish that a lower level shallow trough was persisting over the Gangetic plains through 00 to $12 \mathrm{Z}$. Figure 14 shows one/half hourly satellite images of 22 May. The $08 \mathrm{Z}$ VIS image (figure 14a) hardly shows any presence of convective cloud but 08:30 Z WV image (figure 14b) shows a small bright dot (denoted by white arrow) in A northwest direction from Kolkata. This appears to be the genesis of the storm. The position of the genesis of the storm is close to the location of the low pressure area shown in figure 2(b). As mentioned in section 3 , the genesis of the storm has been influenced by the presence of low pressure area over the Orissa region and the persisting trough in the lower troposphere. In the next $3 \mathrm{~h}$, i.e., at 09,10 and $11 \mathrm{Z}$ (figure $14 \mathrm{c}-\mathrm{e}$ ), the storm is seen to have intensified and moved in a south-eastward direction towards Kolkata. The VIS image of $11 \mathrm{Z}$ (thick arrow named ' 1 ' in figure 14e) is even able to show the shadow of towering cumulonimbus cloud. $11 \mathrm{Z}$ image also shows (thin arrow of figure $14 \mathrm{e}$ named ' 2 ') the 
(a) $08: 48 \mathrm{Z}$

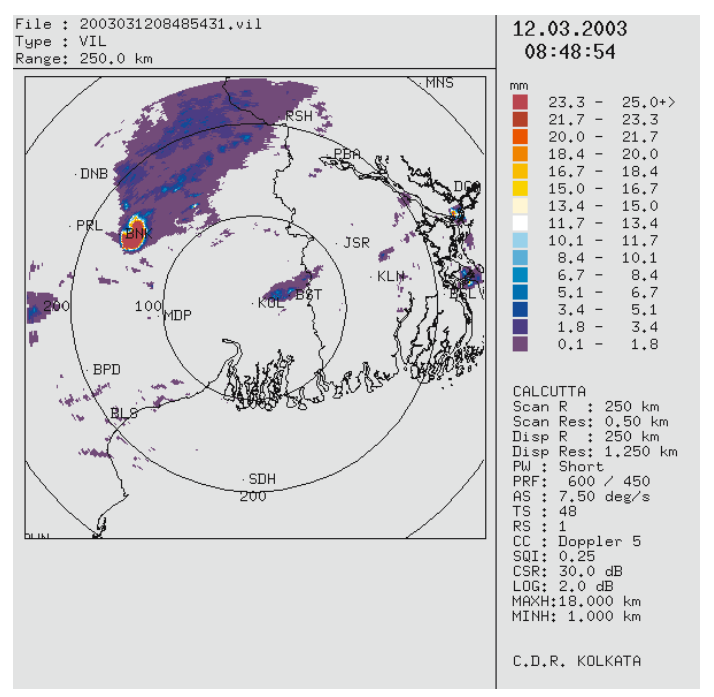

(c) $09: 48 \mathrm{Z}$

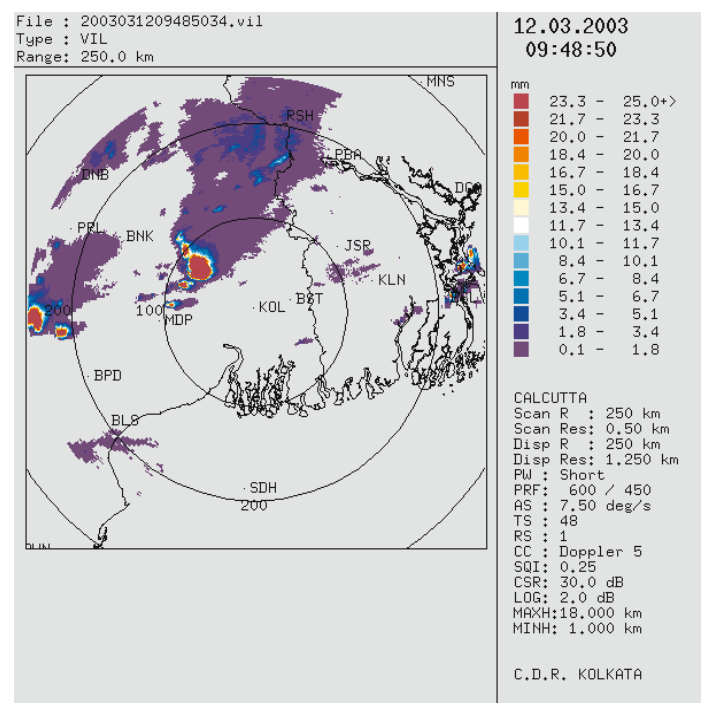

(e) $10: 48 \mathrm{Z}$

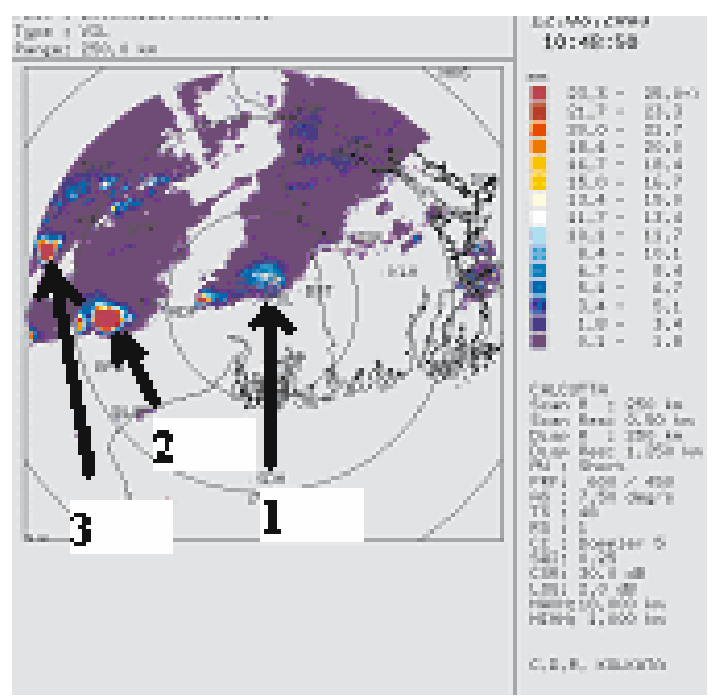

(b) 09:18 Z

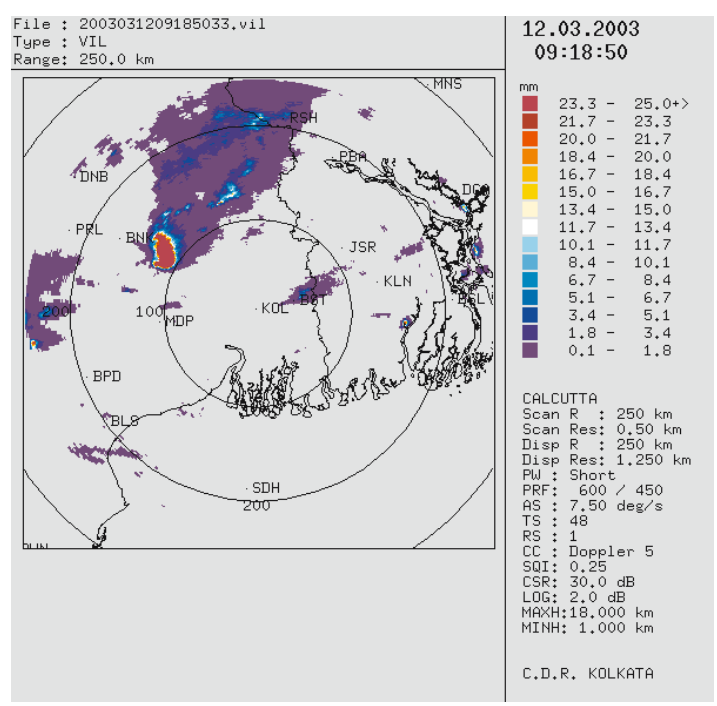

(d) 10:18 Z

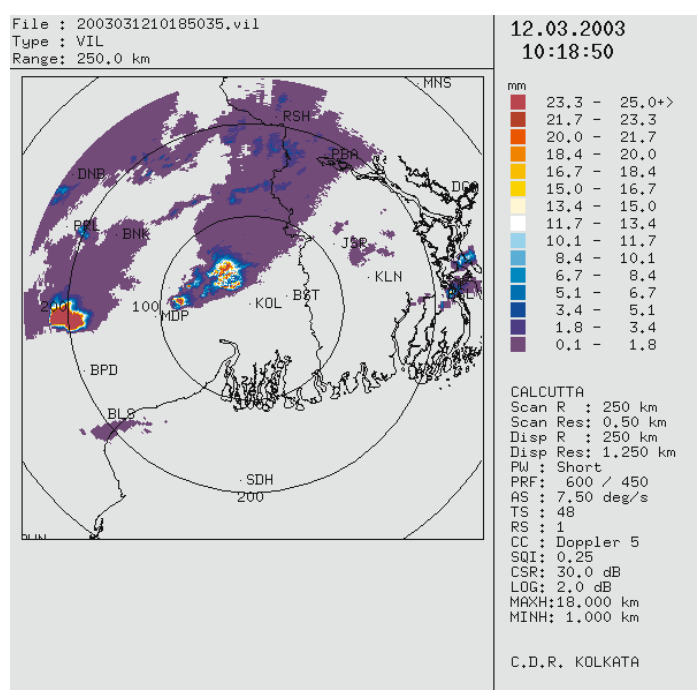

\section{(f) $11: 18 \mathrm{Z}$}

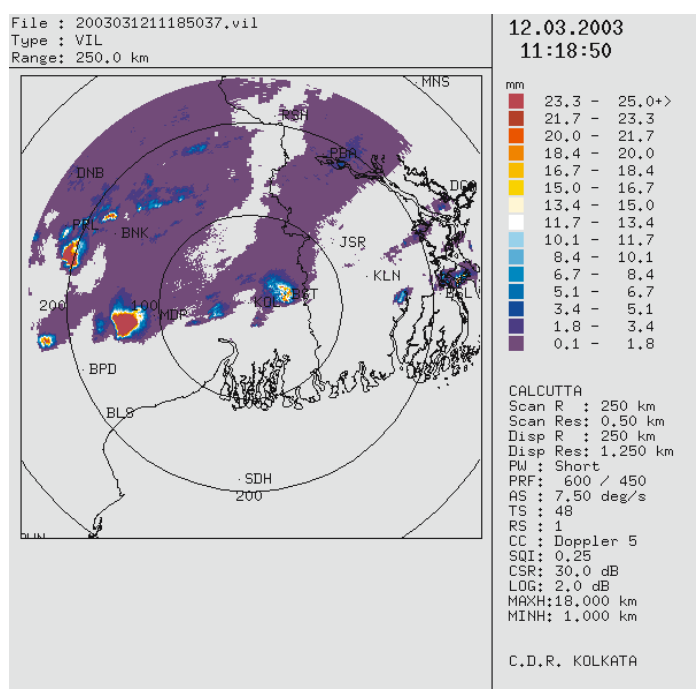

Figure 12. Doppler radar estimated hourly cloud liquid water content of 12 March 2003 Nor'wester. 
(g) $11: 48 \mathrm{Z}$

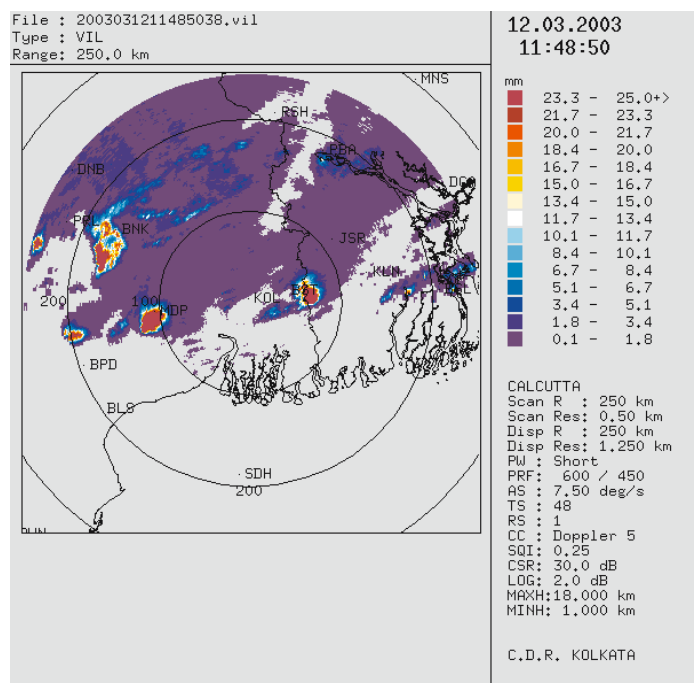

(i) $12: 48 \mathrm{Z}$

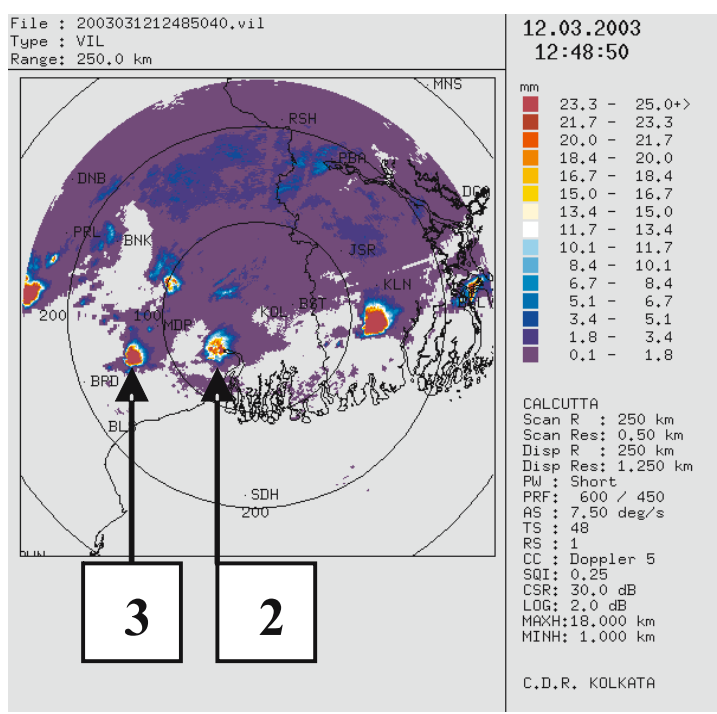

(k) $14: 48 \mathrm{Z}$

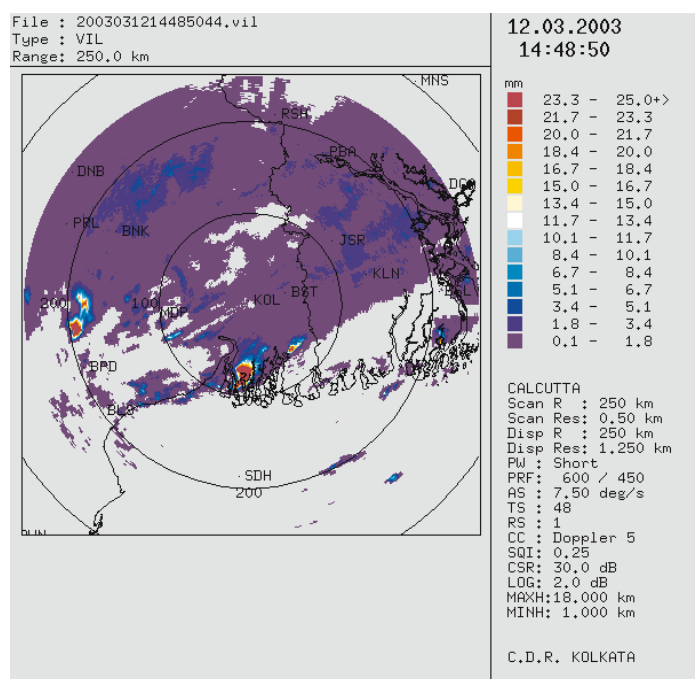

(h) $12: 18 \mathrm{Z}$

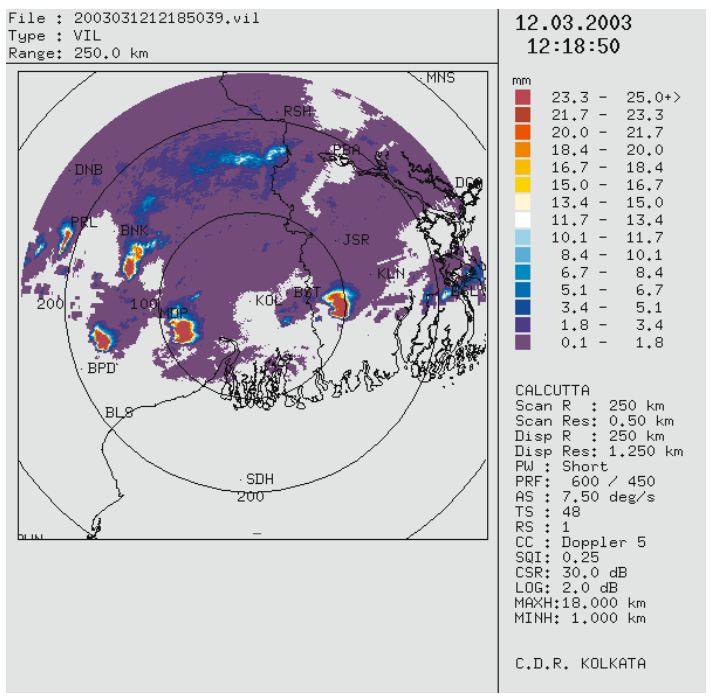

(j) $13: 48 \mathrm{Z}$

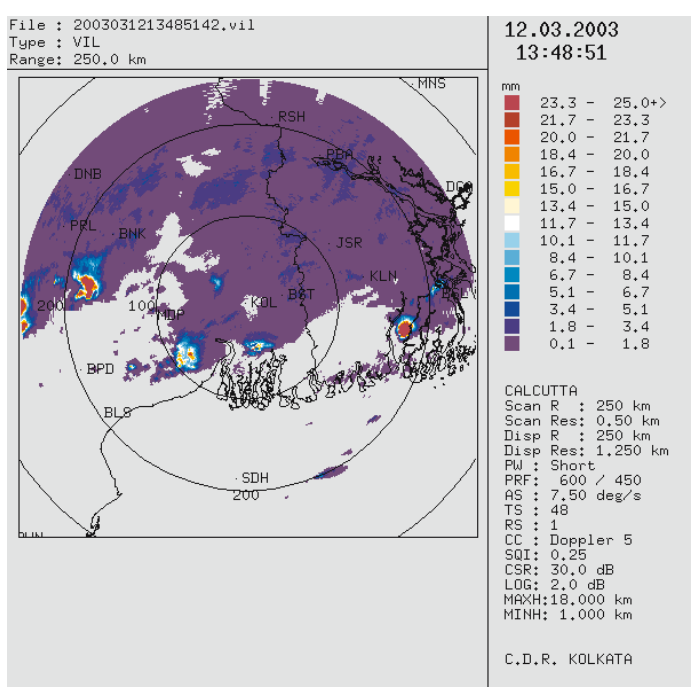

(I) $15: 48 \mathrm{Z}$

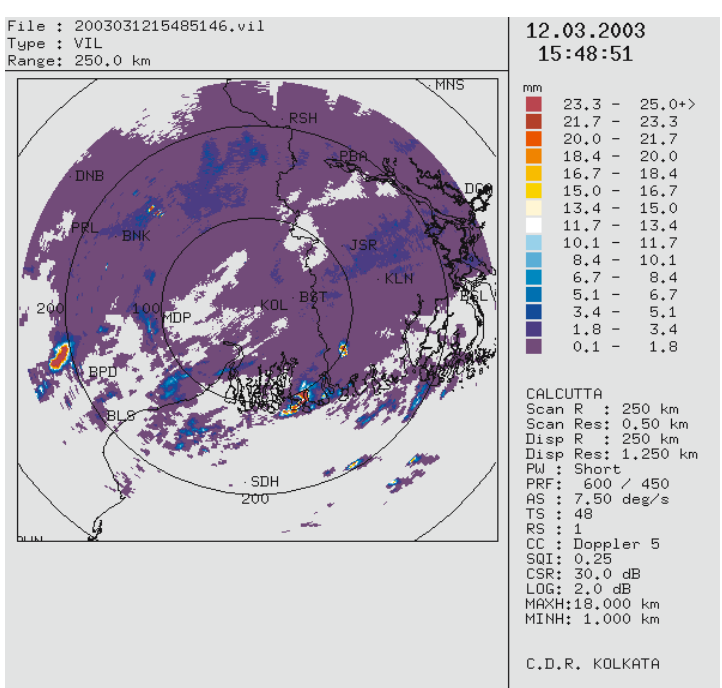

Figure 12. (Continued). 
(a)

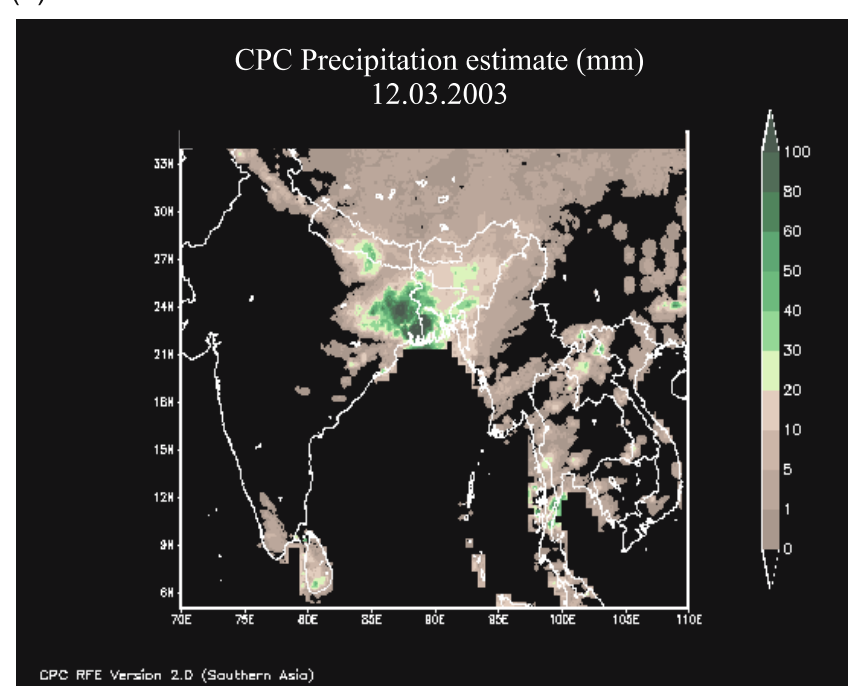

(c)

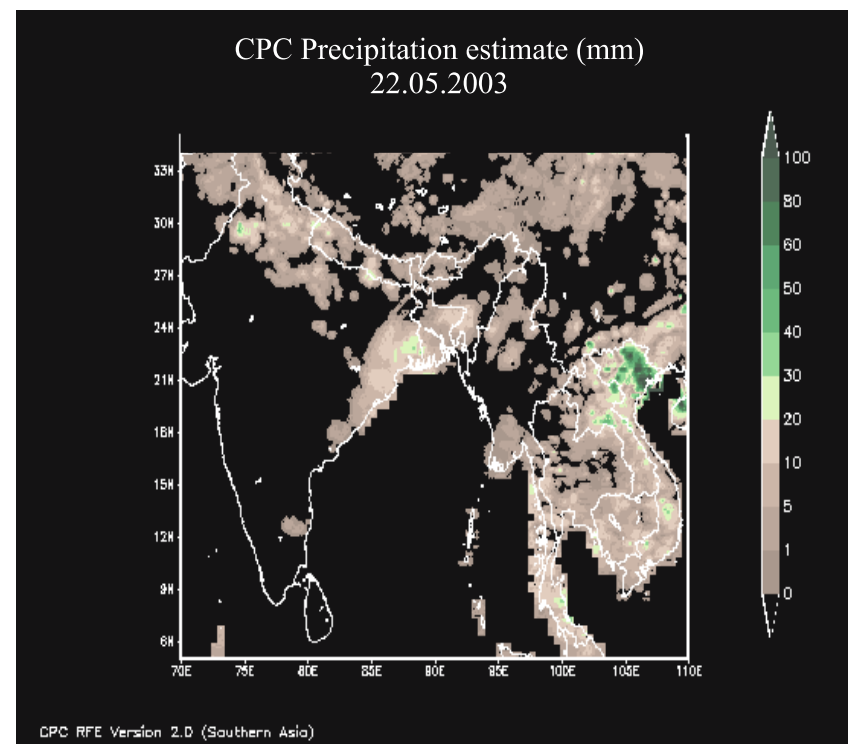

(b) 05:03-16:18Z Accumulated Precip (mm)

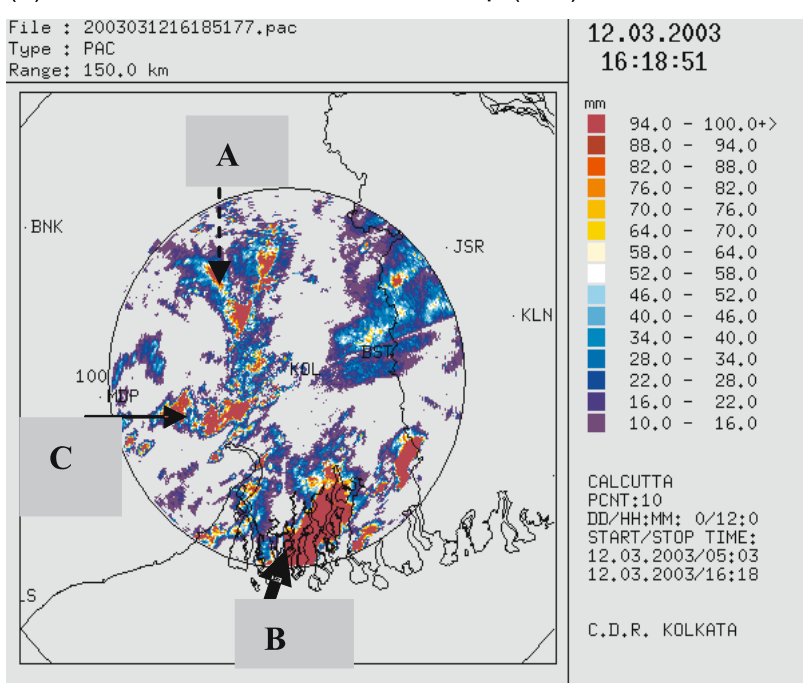

(d) 04:00-16:00Z Accumulated Precip (mm)

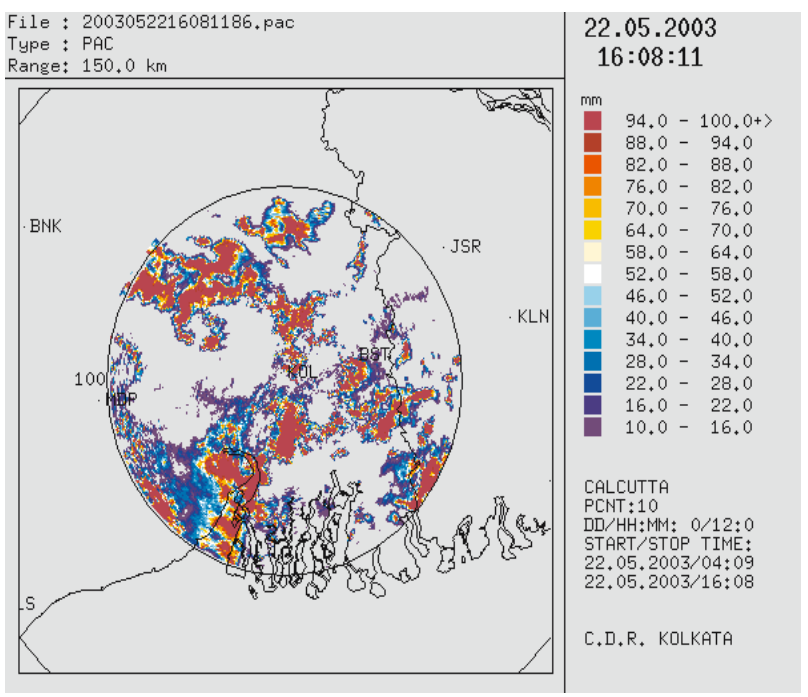

Figure 13. $24 \mathrm{~h}$ accumulated CPC estimated precipitation (a) 12 March 2003, (c) 22 May 2003; Doppler radar estimated $12 \mathrm{~h}$ accumulated precipitation, (b) 12 March 2003, and (d) 22 May 2003.

development of an isolated strong convection very near to Kolkata. At 12:30 Z (figure 14f) these two systems are merged and become an organized mature system at $13 \mathrm{Z}$ (figure $14 \mathrm{~g}$ ). The thunderstorm struck Kolkata and its surrounding with full maturity at round $13 \sim 14 \mathrm{Z}$. The size of the intense convective cloud reveals the strength of the system. The system continued to move in a south-eastward direction during 14, 14:30 and $15 \mathrm{Z}$ (figure $14 \mathrm{~h}-\mathrm{j}$ ) and started losing its strength (dissipation) from $15 \mathrm{Z}$ onwards. During 16 and $17: 30 \mathrm{Z}$ (figure $14 \mathrm{k}, 1$ ) the system moved close to Bay and gradually dissipated. The sequence of satellite images thus is able to capture different phases of the Nor'wester of 22 May.
The DWR observations in hourly sequence are further analyzed to study those features of the storm which are not resolved by the satellite observations, e.g., size, intensity, location and path of movement. No significant convection is detected in the DWR reflectivities during 03-06 Z (figure 15a-d) around Kolkata and this is in good agreement with the satellite observations. However at $09 \mathrm{Z}$, localized feeble convection is seen to have been initiated at around $70 \mathrm{~km}$ northwest to Kolkata (denoted as ' 2 ' in figure $15 \mathrm{~g}$ ). The system intensified by $10 \mathrm{Z}$ (figure 15h) with vertical extension reaching up to $18 \mathrm{~km}$. At $11 \mathrm{Z}$ (figure 15i) system '2' moved south-eastward and was centered around $50 \mathrm{~km}$ northwest of Kolkata. 
(a) $08 Z \mathrm{VIS}$

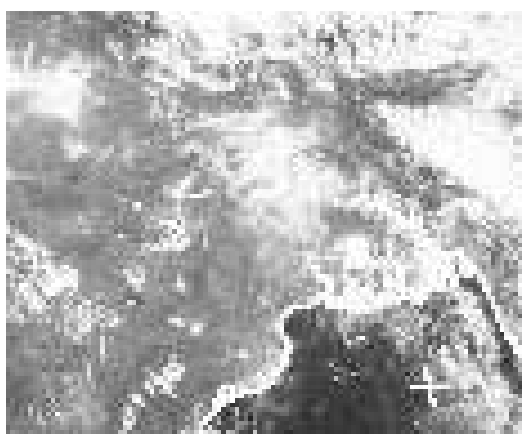

(d) $10 Z$ VIS

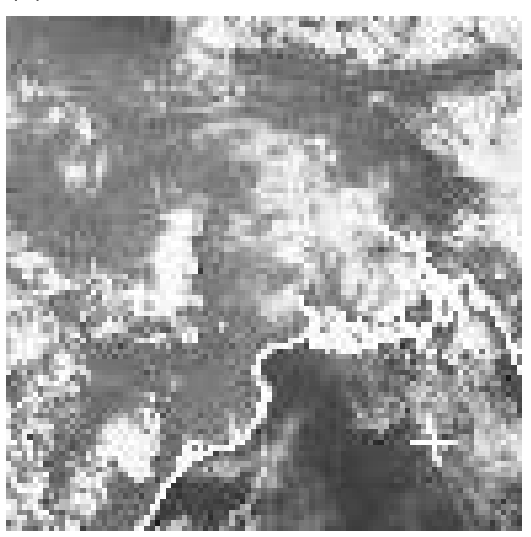

(g) $13 Z$ IR

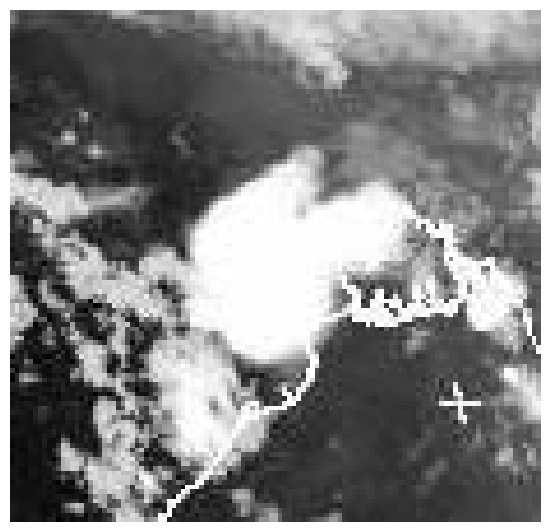

(e) $11 \mathrm{Z} \mathrm{VIS}$

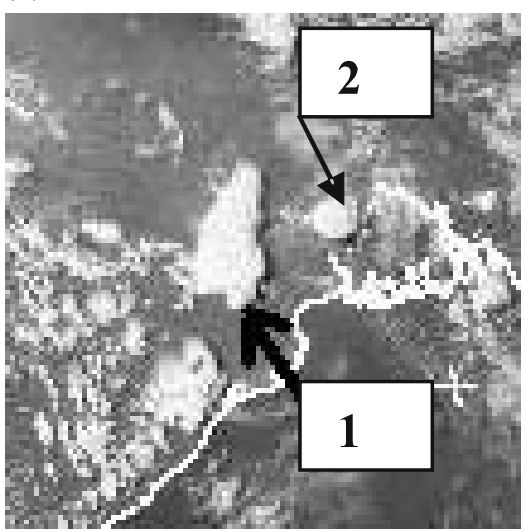

(h) $14 Z$ IR

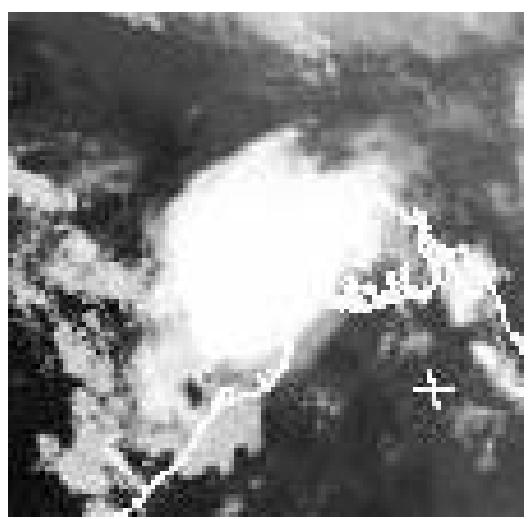

(k) $16 Z$ IR
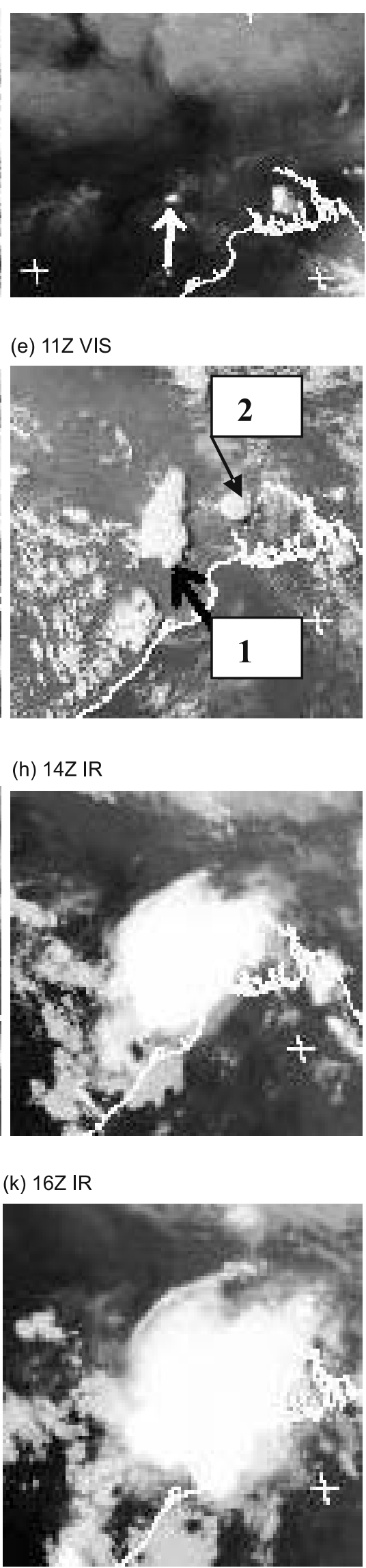

(c) $09 Z \mathrm{IR}$

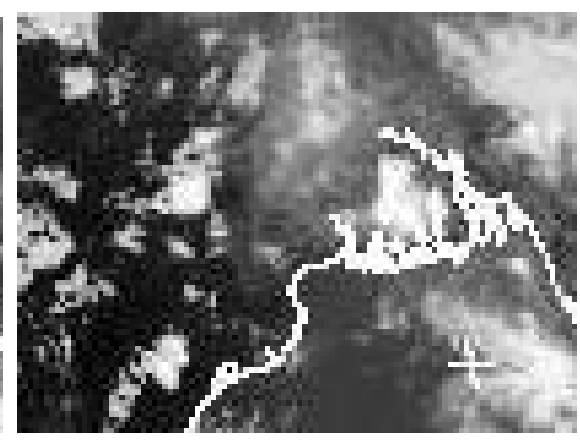

(f) $1230 Z \mathrm{WV}$

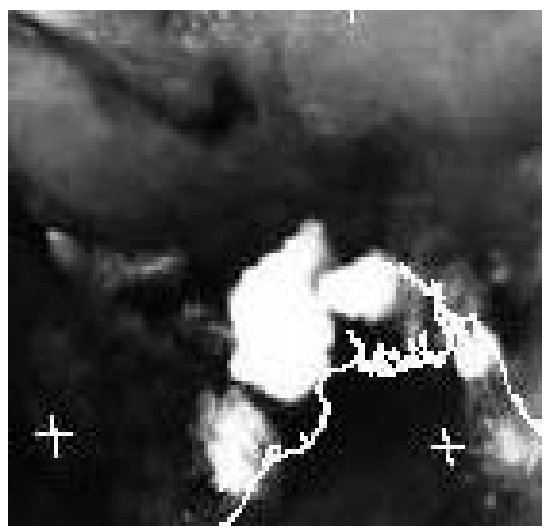

(i) $1430 \mathrm{Z} \mathrm{WV}$

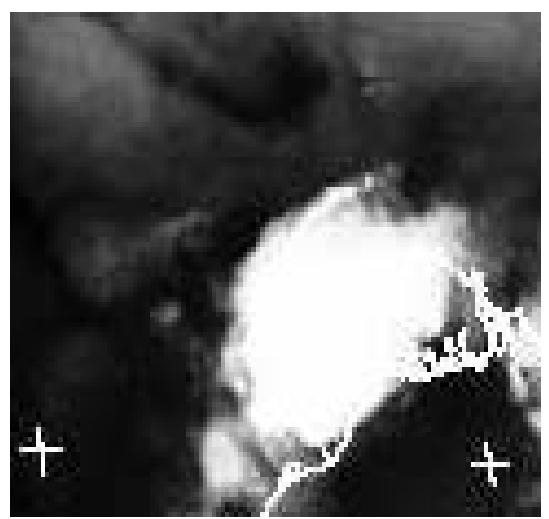

(I) $1730 \mathrm{Z} \mathrm{WV}$

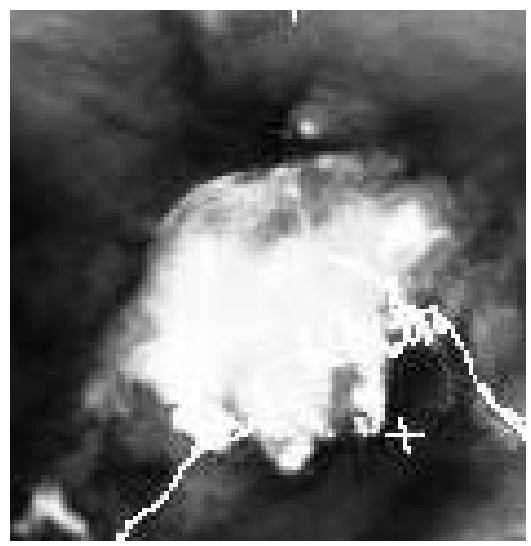

Figure 14. Same as figure 8 but for 22 May 2003. 
(a) $03 Z$

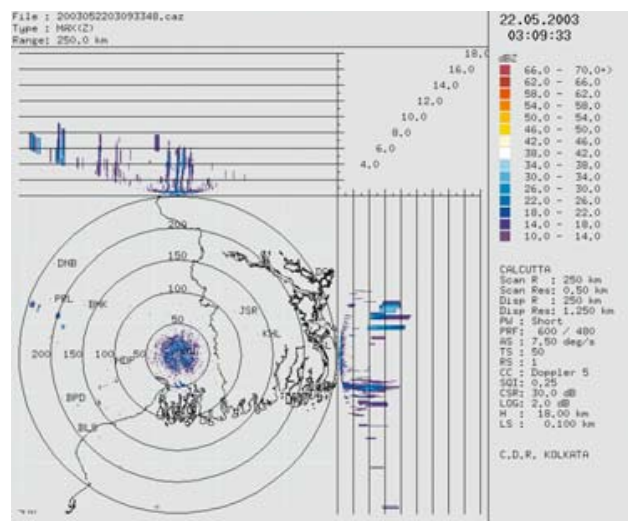

(c) $05 Z$

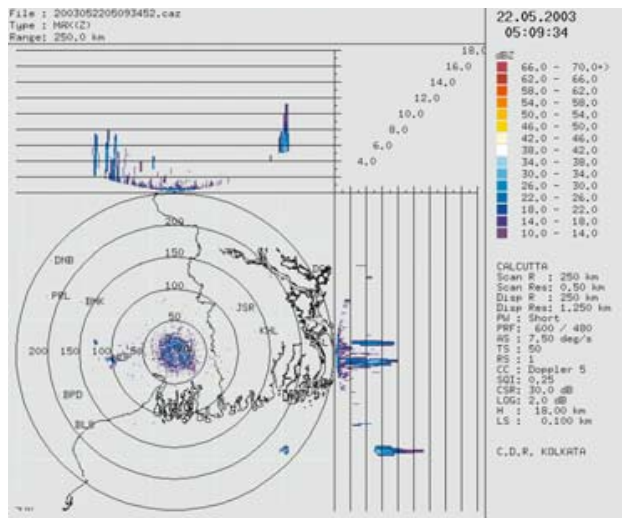

(e) $07 Z$

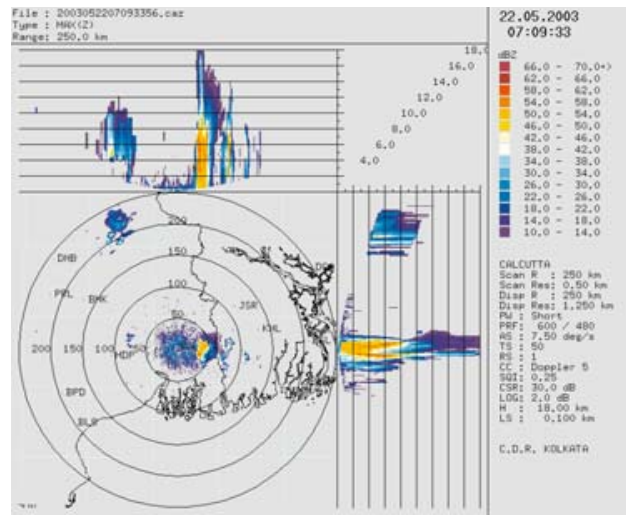

(g) $09 Z$

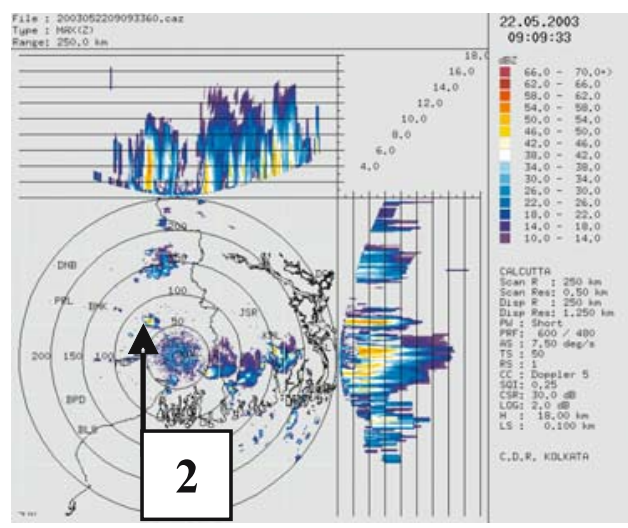

(b) $04 Z$

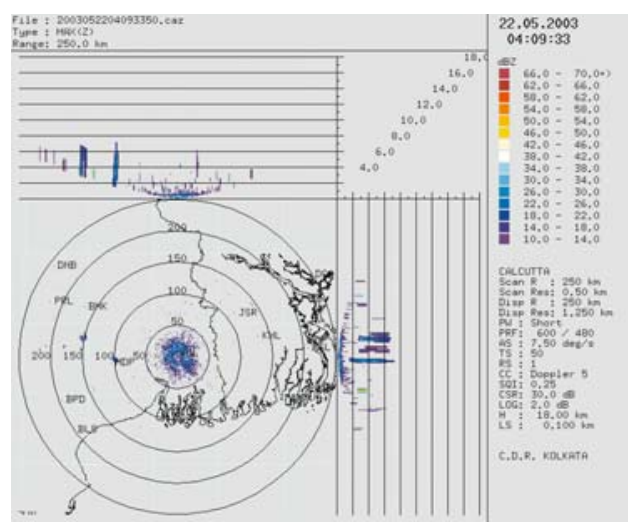

(d) $06 Z$

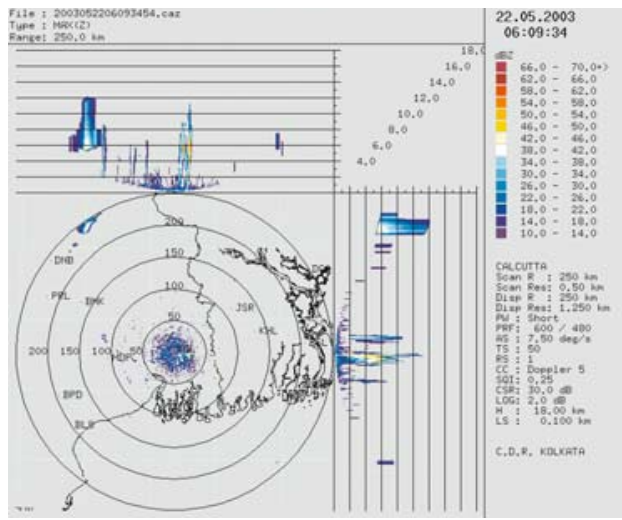

(f) $08 Z$

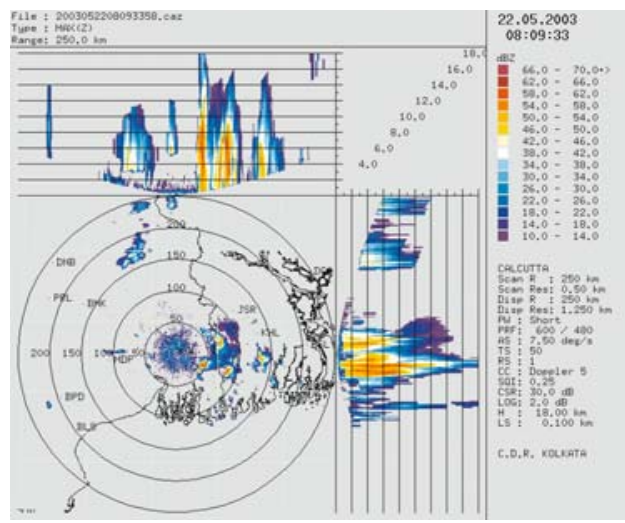

(h) $10 Z$

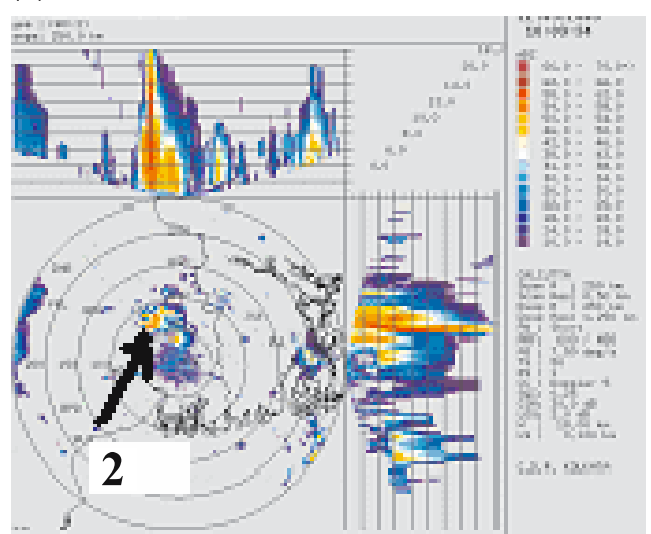

Figure 15. Same as figure 10 but for 22 May 2003. 
(i) $11 Z$

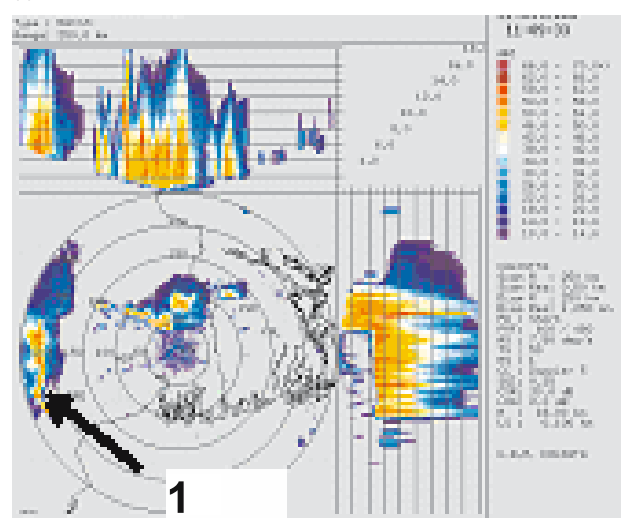

(k) $13 Z$

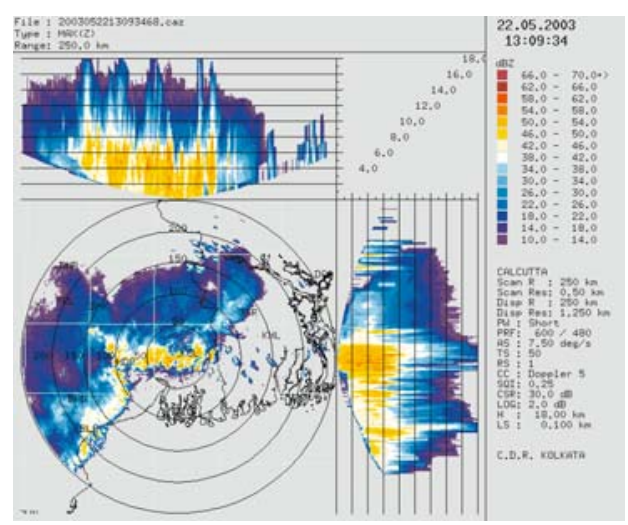

(m) $16 Z$

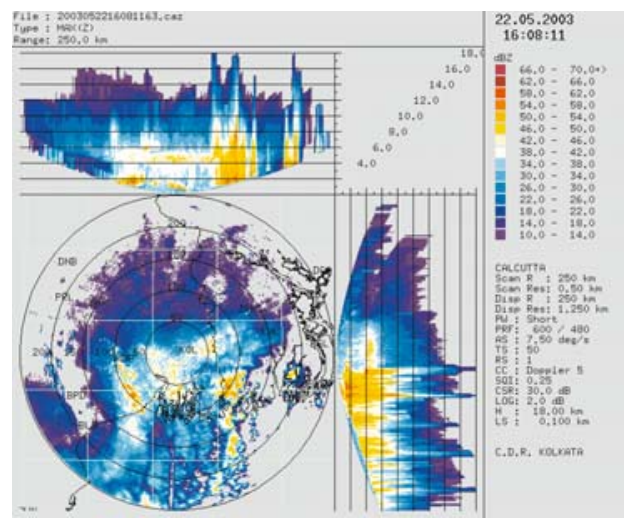

Figure 15.

By this time, another system (denoted as ' 1 ' in figure 15i) appeared $250 \mathrm{~km}$ west of Kolkata. System ' 1 ' approached from the Orissa region after getting triggered by the prevailing low pressure center (figure 2b) and lower level trough. System ' 1 ' is also captured by the satellite observation of $11 \mathrm{Z}$ (denoted by thick black arrow in figure 15e named '2'). The system ' 2 ' which was at $50 \mathrm{~km}$ northwest to Kolkata was detected by the 11:00 Z visible image (figure 14e) also. At 12 and $13 \mathrm{Z}$ system ' 1 ' from the west showed fast movement covering (j) $12 Z$

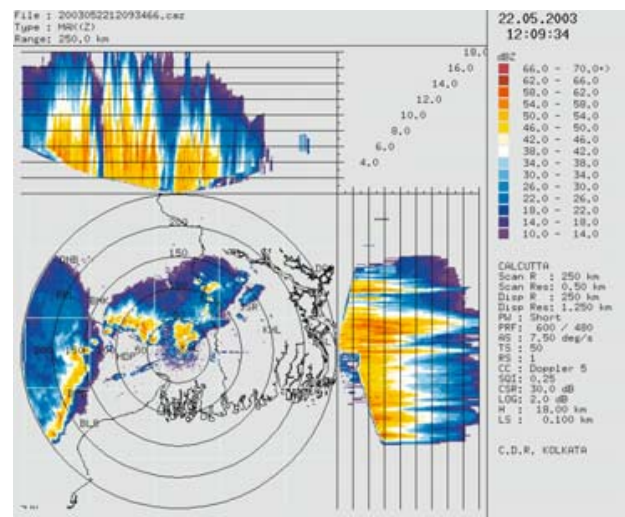

(I) $14 Z$

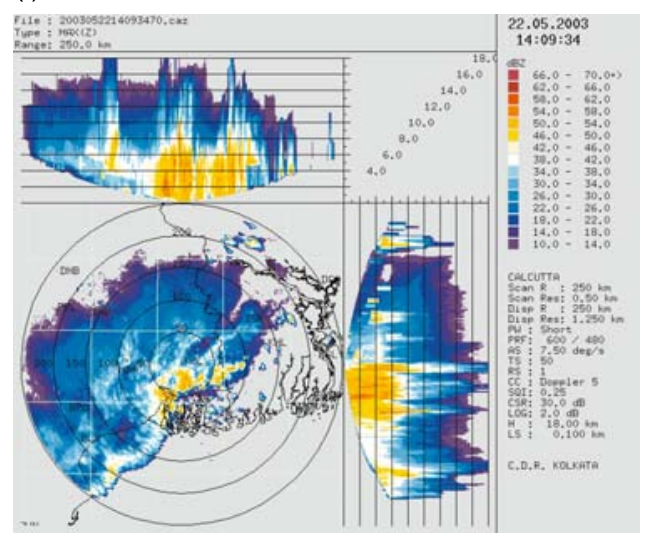

(n) $17 Z$

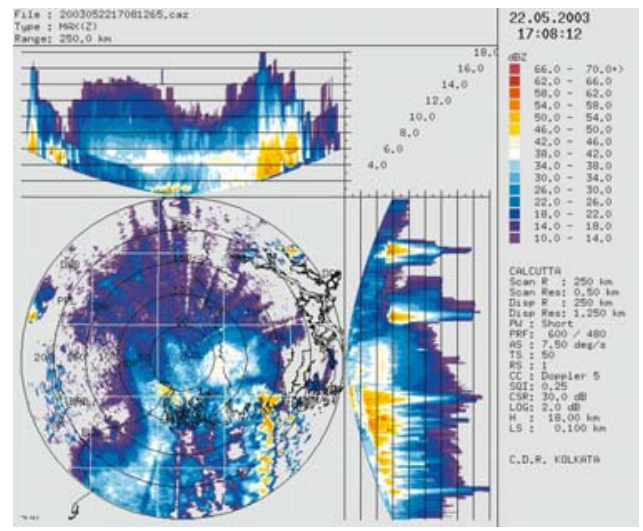

(Continued).

more than $100 \mathrm{~km}$ in $2 \mathrm{~h}$ (figures $15 \mathrm{j}$ and $\mathrm{k}$ ). Rao and Boothalingam (1957) in their study at the time of incidence of Nor'westers at Kolkata mentioned speed of 30-40 mile/h and this they derived from the report of Nor'westers at different stations in Gangetic plains.

System ' 1 ' is found to have split into two with one part moving right towards south and another merging with the system ' 2 ' to finally take the shape of squall lines (figure $15 \mathrm{j}$ and $\mathrm{k}$ ) at 12 and 13Z. The detailed structures of splitting, 
(a) $03 Z$

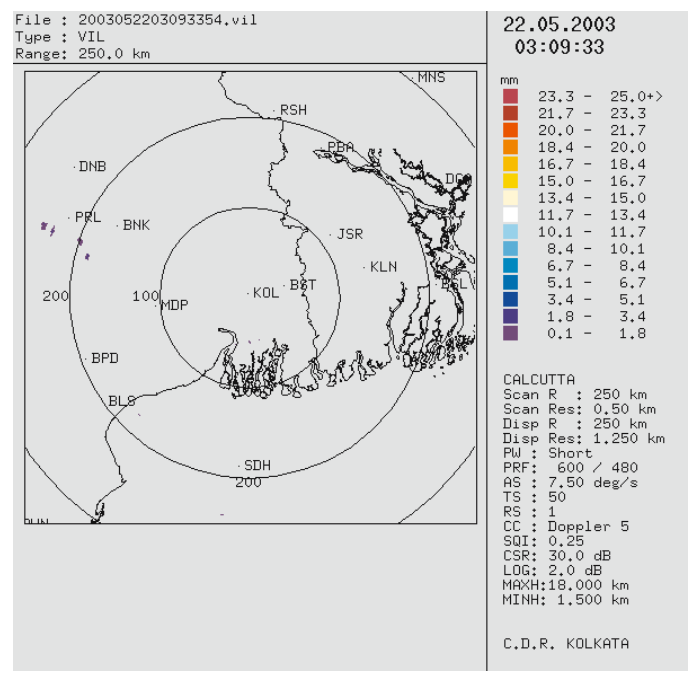

(c) $05 Z$

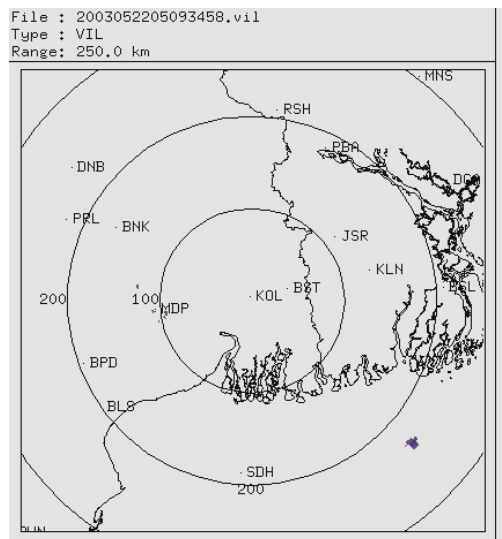

(e) $07 Z$

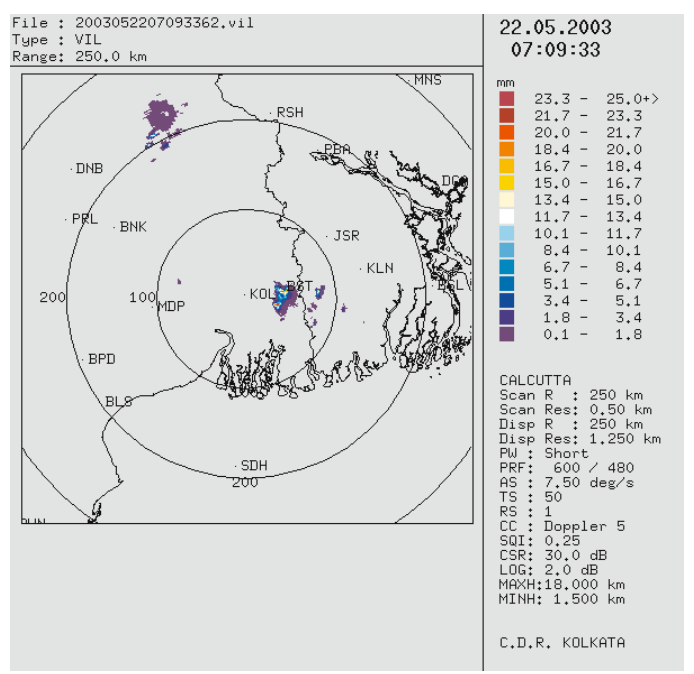

(b) $04 Z$

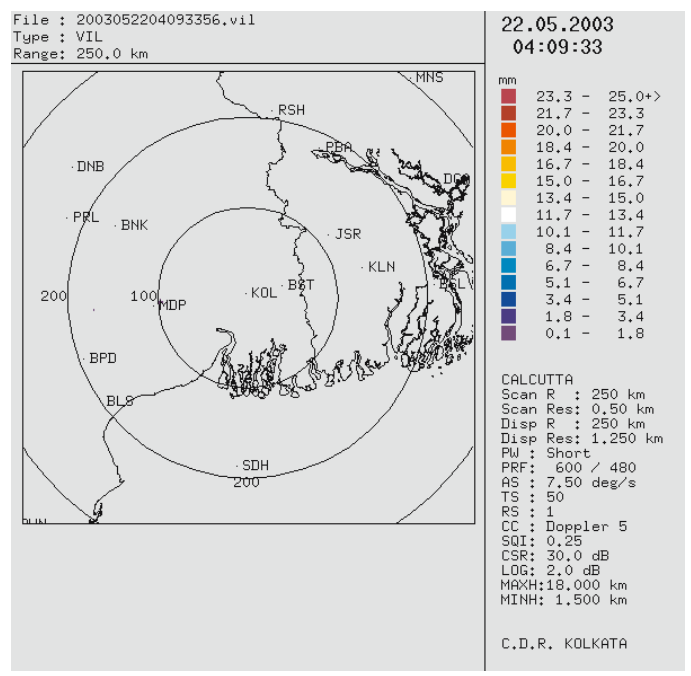

(d) $06 Z$

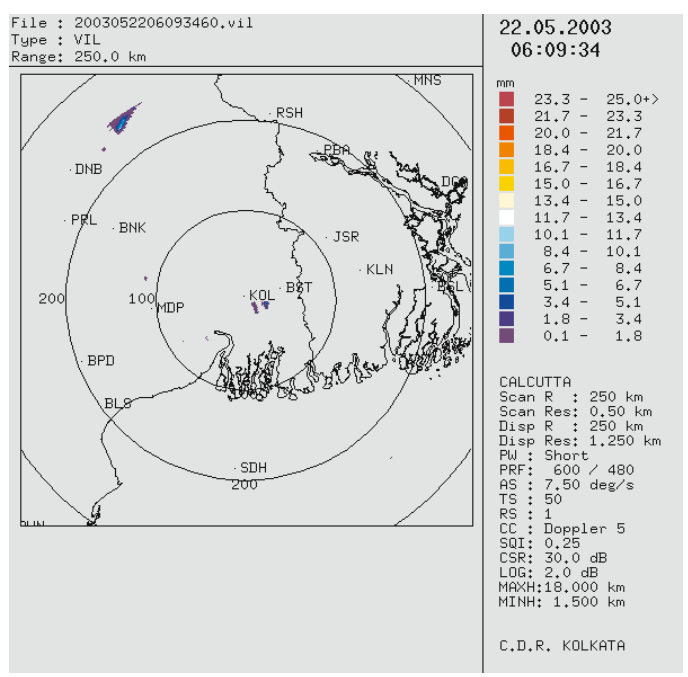

(f) $08 Z$

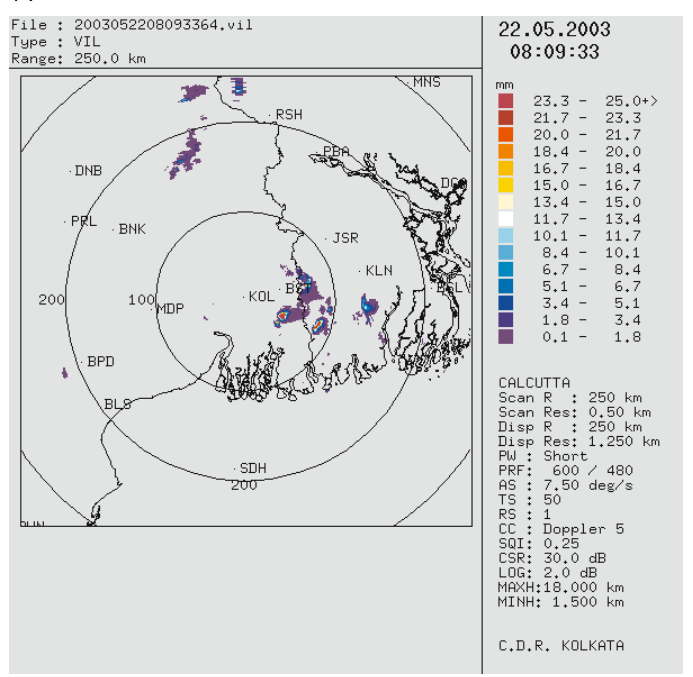

Figure 16. Same as figure 12 but for 22 May 2003. 
(g) $09 Z$

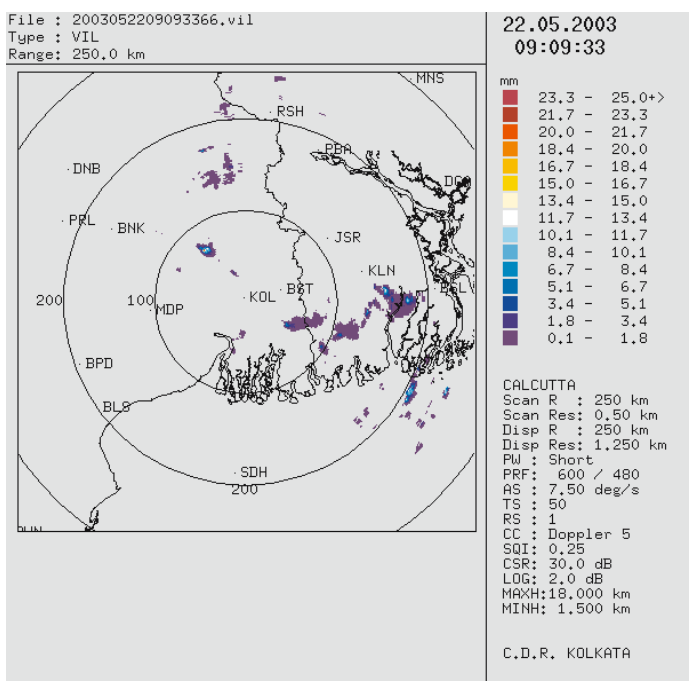

(i) $11 \mathrm{Z}$

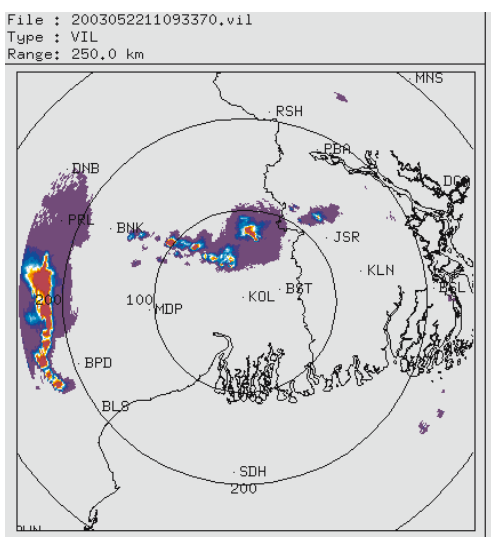

(k) $13 Z$

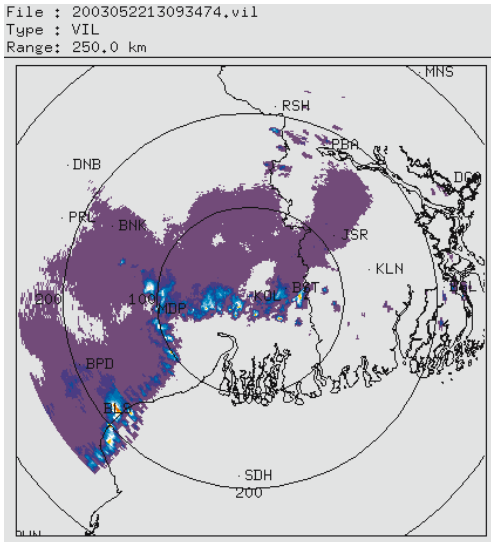

(h) $10 Z$

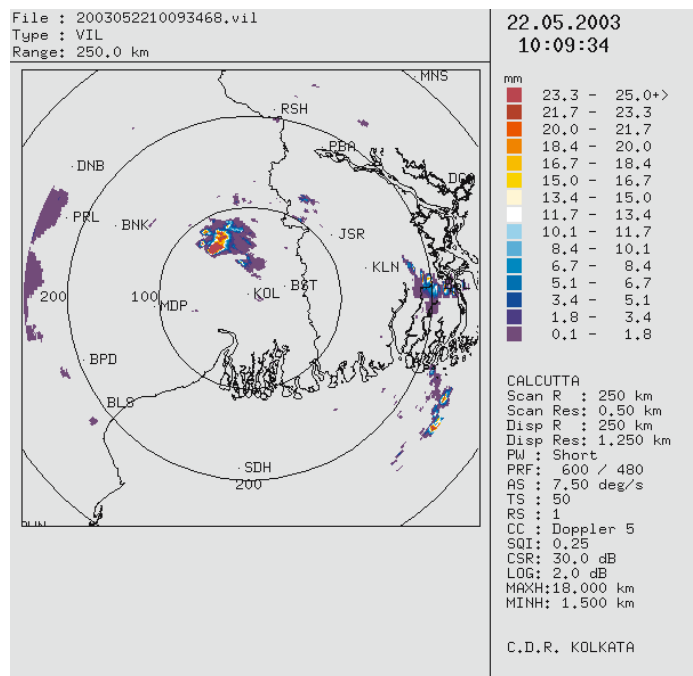

(j) $12 Z$

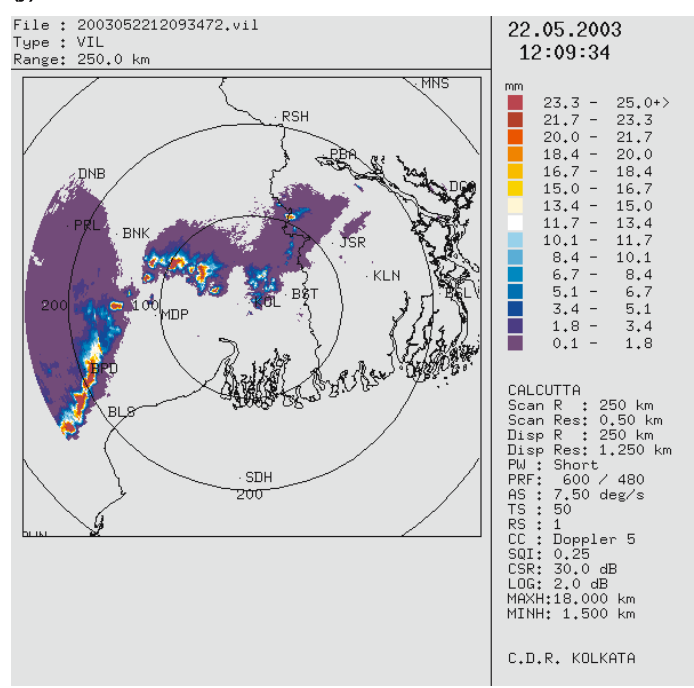

(I) $14 \mathrm{Z}$

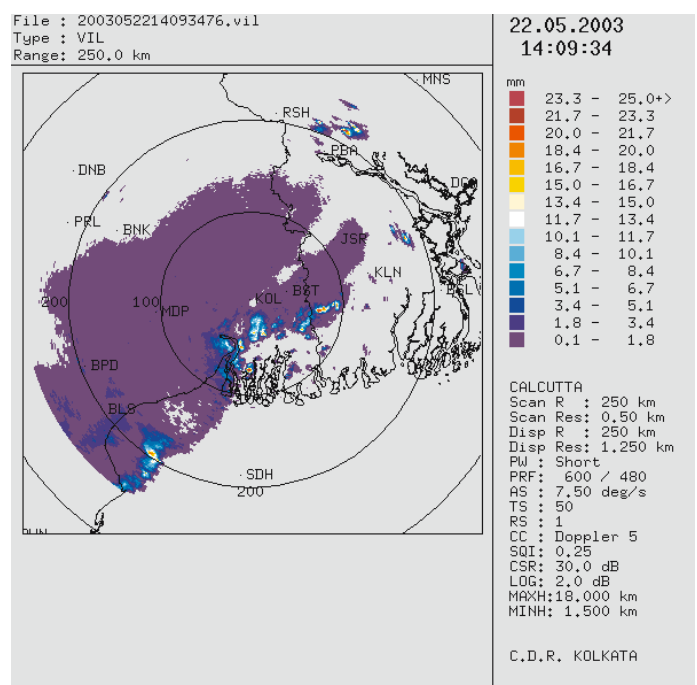

Figure 16. (Continued). 
(a) 112

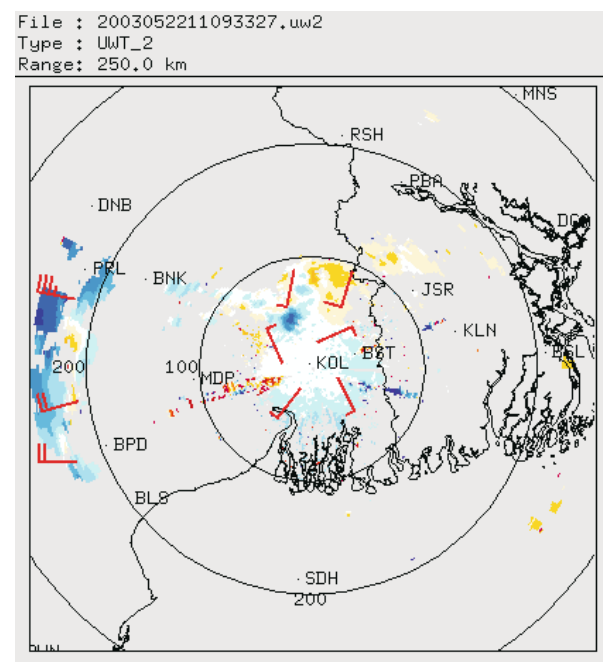

(c) $13 Z$

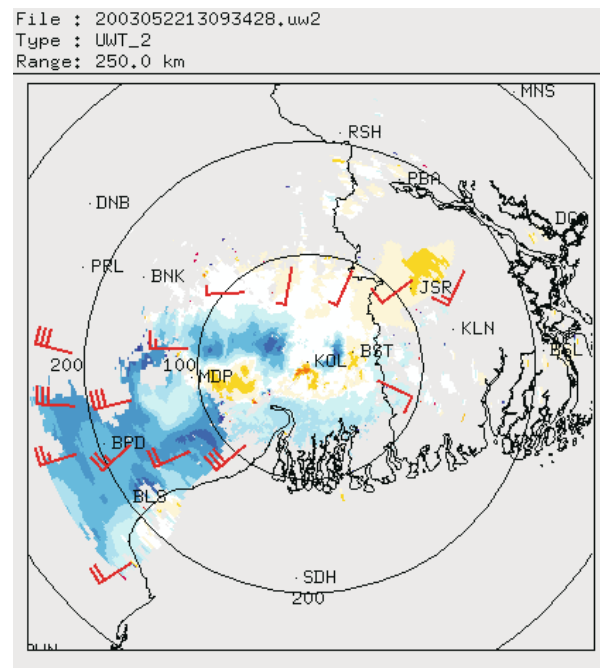

22.05 .2003 $13: 09: 34$

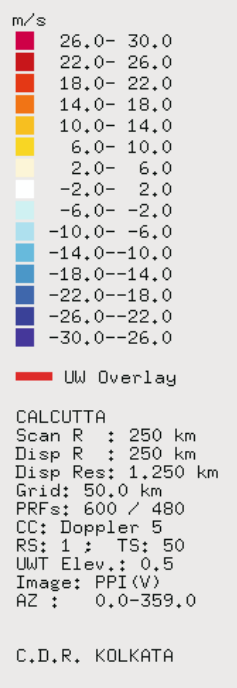

(b) $12 Z$

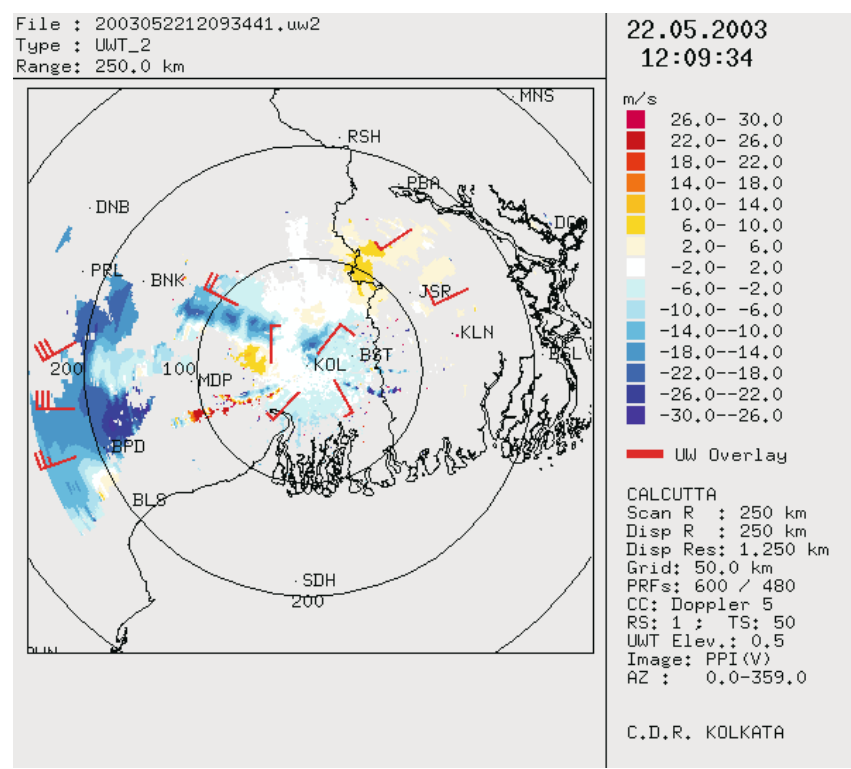

(d) $14 Z$

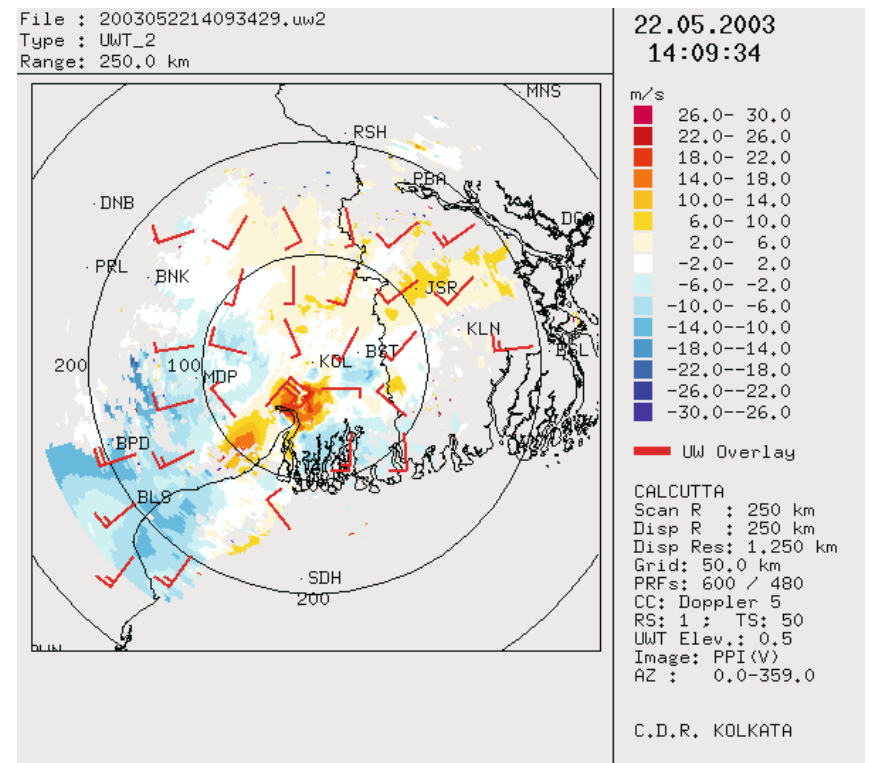

Figure 17. Doppler derived horizontal wind vectors superimposed on vertical velocity (shaded) for 22 May 2003 event.

merging of the cells and formation of squall lines are well resolved by the DWR observations and these details are not available by the hourly satellite images. The squall line crossed Kolkata at $13 \mathrm{Z}$ and showed weakening by $16 \mathrm{Z}$ (figure $15 \mathrm{~m}$ ) and dissipated completely by $17 \mathrm{Z}$ (figure $15 \mathrm{n}$ ). The upper air data (figure not shown) of Kolkata at 00 and $12 \mathrm{Z}$ suggests that the atmosphere was unstable throughout the day as reflected by the CAPE value from $1004 \mathrm{~J} / \mathrm{kg}$ at 00:00 to $2063 \mathrm{~J} / \mathrm{kg}$ at $12 \mathrm{Z}$.

The location of initiation, movement, merging, splitting, maturity and dissipation are captured by the hourly LWC (figure 16a-i) also. Formation of system ' 2 ' (figure $16 \mathrm{~g}$ ) at $09 \mathrm{Z}$, intensification in subsequent hours at 10 and $11 \mathrm{Z}$ (figure $16 \mathrm{~h}, \mathrm{i}$ ) and merging with the system ' 1 ' at $12 \mathrm{Z}$ (figure $16 \mathrm{j}$ ) are captured in detail and in tune with the figure 15 of DWR reflectivities. At $10 \mathrm{Z}$ the system was located around $50 \mathrm{~km}$ northwest to Kolkata with high LWC value of $20 \mathrm{~mm}$. During the next hour the system splits into multi-cell ( 8 in numbers) each having high $\mathrm{LWC}$ value. The multi-cell system aligns along east-west direction. The east-west oriented multi-cell system merged with another approaching system from the west and the combined squall lines crossed Kolkata at $13 \mathrm{Z}$. 


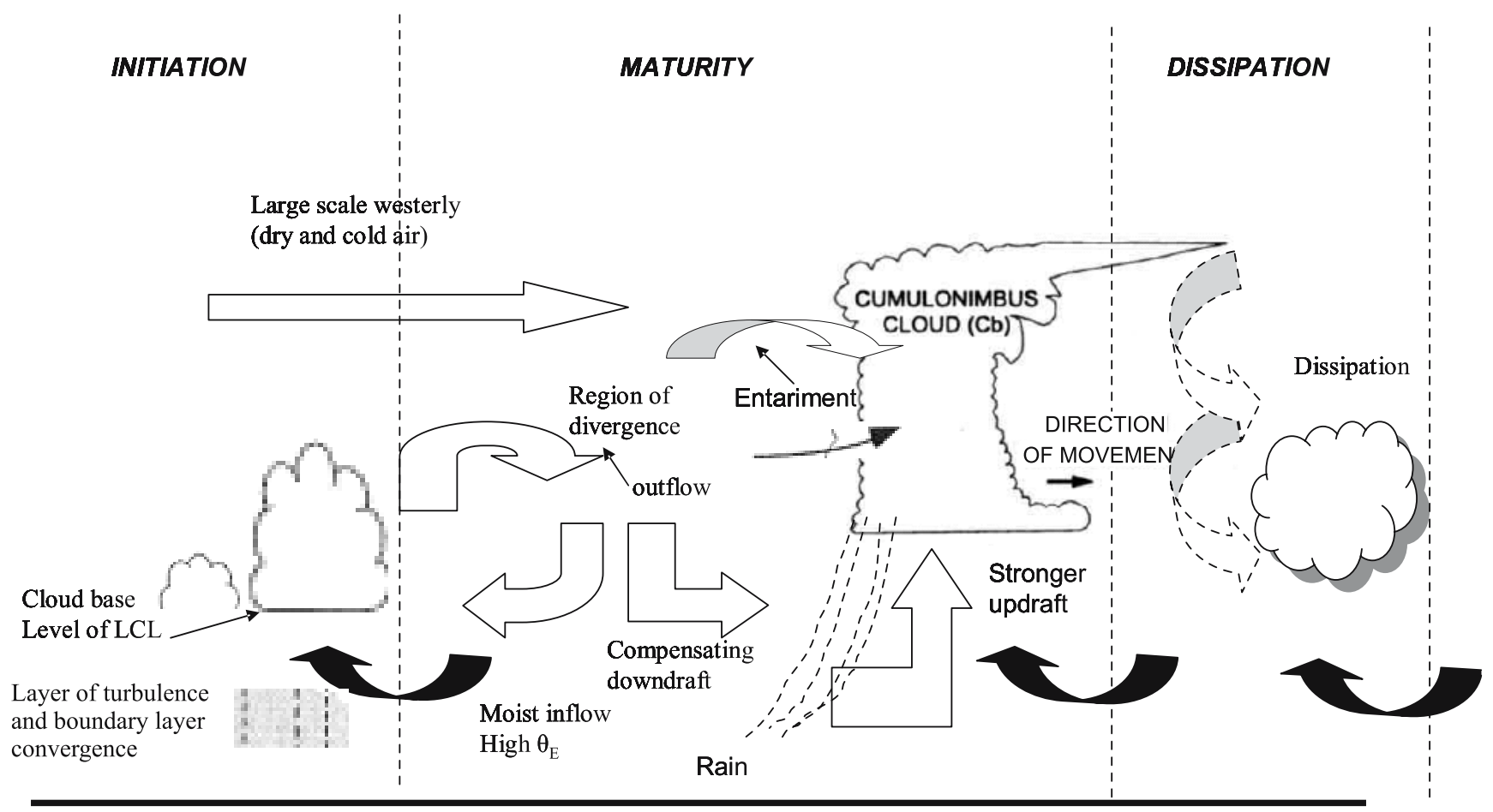

Figure 18. Schematic explaining the different processes at various stages of Nor'wester.

The answer to the splitting and formation of new cells may be obtained from the wind flow patterns around the systems. At $11 \mathrm{Z}$ the region $(100 \mathrm{~km}$ circle) was under the strong influence of the convective downdraft of the system approaching from the west. The wind vectors over Kolkata also show strong cyclonic curvature and convergence. At $12 \mathrm{Z}$ (figure 17b) the wind vector shows higher magnitude and the subsidence is clearly seen by the negative sign of the vertical velocity. By $13 \mathrm{Z}$, the convective downdraft reached very near to Kolkata which is evident by the extension of the shaded negative area. Thus the formation of multi-cell may be attributed to the strong convective downdraft over a large area and leading to boundary layer convergence and updraft at multiple places.

The 24-h accumulated CPC precipitation $(\mathrm{mm})$ and 12-h accumulated DWR precipitation estimate $(\mathrm{mm})$ are compared in figure 13(c) and 13(d). The rainfall over Kolkata and surrounding is found to be of the order of $30-40 \mathrm{~mm}$ in CPC estimate (figure 13c). The Doppler radar shows a detailed spatial rainfall distribution which is not captured in CPC estimate. The rainfall distribution from Doppler radar shows maximum values along the path of the squall line. North and south of Kolkata appears to receive very heavy rainfall $(90 \mathrm{~mm})$. The observation by the IMD also suggests $73 \mathrm{~mm}$ of rain due to the event. Thus, the rainfall estimate appears to be reasonably accurate in terms of quantity and location.

\section{Hypothesis}

Browning (1964) proposed one of the first conceptual model of severe local storm. His model showed wind turns (volt) cyclonically by $270^{\circ}$ within the updraft and comes out along with the shear and subsequently the downdraft appears within the precipitation area ahead of updraft which causes cold and dry mid level air to approach from the right flank. As a result the storm moves towards right with respect to the mid level wind. Marwitz (1972a, b, c) in a series of three papers established Browning's model and further explained the subcloud layer wind speed $(\sim 8 \mathrm{~m} / \mathrm{s})$, extent of wind veering $\left(270^{\circ}\right)$ and discrete and propagation of cells. It is mentioned by many authors that mid latitude storms are generally formed in a strong baroclinic environment with surface frontal wave, jet stream at upper troposphere and substantial potential vorticity anomaly.

Analyses of the Doppler radar, satellite and conventional radisonde observations, bring out a different picture for the formation, sustenance and propagation of Nor'westers. The mechanism of Nor'wester formation and the role of large scale and mesoscale environment is conceptually put forward here. The large scale atmosphere over Indian region in general and Gangetic plains in particular frequently come under the influence of eastward propagating shallow lower level troughs. The troughs are embedded over westerlies and 
many time extend upto $20.0^{\circ} \mathrm{N}$. The passage of troughs can provide the cyclonic shear to the lower level $(850-700 \mathrm{hPa})$ wind leading to local convergence. The Bay of Bengal region during this time shows a presence of lower level anticyclone which advects warm and moist wind into the Gangetic plains. The inflow of moist and warm southerly in the lower level of the troposphere increases the conditional instability over the region. Strong solar insolation heats up the Bihar plateau which behaves as local elevated heat source to further provide lift to unstable airmass. The wind in the subcloud layer $(\sim 1.5 \mathrm{~km})$ is found to be around $15 \mathrm{~m} / \mathrm{s}$. These are the effects which are contributed by the large scale environment towards building up of instability over the mesoscale region which is bound in the northwest by Bihar plateau and Bay of Bengal in the south. The initial forcing by the large scale environment culminates sometime in triggering moist convection depending upon the processes within the boundary-layer. The lower level inversion, convergence, strong sensible heat flux can set in the convection. The lower level $(850 \mathrm{hPa})$ southerly and upper level $(100 \sim 200 \mathrm{hPa})$ westerlies provide a sheared environment for convective overturning to happen. The veering of the wind is seen to be of the order of $135^{\circ}$ which is much lesser than that reported by Browning (1964) and Marwitz (1972a, b, c). The initial development of cumulus cloud leads to further development of convective cells out of their compensating downdraft. The storm sometimes in the form of discrete cells (as in the event of 12 March 2003) and sometimes as squall line (event of 22 May) moves at a speed of $23 \sim 25 \mathrm{~m} / \mathrm{s}$. The adiabatically compressed air from compensating downdraft along with prevailing southerlies (high $\theta_{E}$ ) cause stronger convergence in the boundary layer which produces deeper convection. The upper level $(200 \mathrm{hPa})$ westerlies facilitate upper level divergence and in turn helps the lower level convergence to further organize. The system continues to gather strength and becomes a self sustaining system till the boundary-layer source is cut-off. This happens in the late afternoon when the sensible heat flux reduces, the warm and moist inflow from Bay also reduces and the atmosphere starts releasing the CAPE leading to dissipation of the system. The storms are found to move right in some cases after reaching around Kolkata at its dissipating phase. At this point the convergence in the lower level occurs at the right as the lower level moist inflow comes from the Bay and the storm follows the path. The precipitation precedes the system and appears in the rear of the storm along with hails and cold down draft. The mechanism mentioned here is schematically depicted in figure 18. The part-II of this paper will be attempted to show the processes put forward in the hypothesis using a mesoscale model at cloud resolving resolution.

\section{Conclusion}

The structure and evolution of two severe Nor'westers that struck Kolkata city on 12 March and 22 May 2003 have been studied using hourly satellite imageries and DWR observations. The Nor'wester of 12 March happened to be one of the severest in the recent past. The paper brings out that satellite or DWR alone may not be able to capture the life-cycle of Nor'westers due to their inherent limitations, however, combined information from both can resolve the same. The Nor'westers of 12 March got triggered by a dry line influenced by a cyclonic circulation in the large scale atmosphere whereas that of 22 May was triggered by the lower level convergence due to the presence of a low pressure center in the surface and trough in the lower and middle troposphere. The Nor'wester of 12 March approached Kolkata from a northwesterly direction than that of 22 May which appeared much to the west with respect to Kolkata. On 12 March consecutive 3 Nor'wester cells formed and struck Kolkata and the dynamical mesoscale features of the cells are captured in detail by DWR observations. The vertical structure of each system, path of movement, potential of localized heavy rain by each cell and spatiotemporal distribution of precipitation are brought out by the DWR observations. The 22 May event is an ideal example that shows how a convective cloud that appeared as a dot in the satellite images of $08 \mathrm{Z}$ can get transformed into multi-cell storm and further becomes a squall line at $13 \mathrm{Z}$. The system continuously gathered strength till it dissipated at $16 \mathrm{Z}$ after crossing the Kolkata city at $13 \mathrm{Z}$. These Nor'westers are driven by convective instability which is initiated by the large scale perturbation such as low pressure centers and trough in these cases. It is also found that these two systems have a size that affected the very wide area of around $100 \mathrm{~km}$ radius around Kolkata and also affected the towns and cities along its path of movement. The vertical extent of the Nor'westers are found to reach up to $16-18 \mathrm{~km}$ at its initial and maturity and gradually decreases during dissipation. The peculiarities between the two Nor'westers namely one (12 March event) had more than one cells lined up one behind the other and in another (22 May event) it is number of thunderstorm cells (eight) aligned in a line to form a squall line, are brought out by the DWR observations. This study thus establishes the fact that composite information of hourly Doppler radar observations and high 
resolution satellite imageries can be used together to explore many features of the Nor'westers which otherwise remain unnoticed due to the lack of high density observational network. For the first time a conceptual model is proposed explaining different physical processes that dominates at different stages of the storms and this will help in understanding these fury of natures.

\section{Acknowledgements}

The authors are thankful to the Director, Indian Institute of Tropical Meteorology (IITM), Pune, India, for his interest, encouragement and suggestions in this study. Authors are thankful to the Head, Forecasting Research Division for his keen interest. Authors are thankful to the Director General, India Meteorological Department for giving access to Doppler radar observations. First author acknowledges Dr S K Kundu, IMD for his help in utilizing Doppler radar observations. Figure 4 is downloaded from the website http://www.bangladeshtornadoes.org/. The reports of damages are taken from the website of The Telegraph (http://www.telegraphindia.com) and The Statesman daily newspaper. The map of West Bengal and its districts is taken from the website www.mapsofindia.com.

\section{References}

Bhatnagar A K, Rajesh Rao P, Kalyanasundaram S, Thampi S B and Gupta J P 2003 Doppler radar A detecting tool and measuring instrument in meteorology; Curr. Sci. 85 256-264.

Bose B L 1957 The Nor'wester and the lower level convergence; Ind. J. Meteor. Geophys. 8 391-398.

Browning K A 1964 Airflow and precipitation trajectories within severe local storms which travel to the right of the winds; J. Atmos. Sci. 21 634-639.

Das P M, De A C and Gangopadhyaya M 1957 Movements of two Nor'westers of West Bengal: A radar study; Ind. J. Meteor. Geophys. 8 399-406.

De A C, Das P M and Gangopadhyaya M 1957 Regenerative drift of a thunderstorm squall of the southwest monsoon season; Ind. J. Meteor. Geophys. 8 71-80.

Desai B N 1950 Mechanism of Nor'westers of Bengal; Ind. J. Meteor. Geophys. 1 74-76.

Dostalek J F, Weaver J F and Phillips G L 2004 Aspects of a tornadic left-moving thunderstorm of 25 May 1999; Wea. Forecasting $19614-626$.

Floyd J 1838 Account of the hurricane or whirlwind of the 8 April 1838; J. Asiatic Soc. Bengal 7 422-429.

Ghosh A, Lohar D and Das J 2008 Initiation of Nor'wester in relation to mid-upper and low-level water vapor patterns on METEOSAT-5 images; Atmos. Res. 87 $116-135$.
Gonski R F, Woods B P and Korotky W D 1989 The Raleigh tornado - 28 November 1988. An operational perspective; Preprints, 12th Conf. Wea. Analysis and Forecasting (Monterey, CA), Amer. Meteor. Soc. 173-178.

Hane C E, Bluestein H B, Crawford T M, Baldwin M E and Rabin R M 1997 Severe thunderstorm development in relation to along-dryline variability: A case study; Mon. Wea. Rev. 125 231-251.

Kennedy P C and Detwiler A G 2003 A case study of the origin of hail in a multicell thunderstorm using in situ aircraft and polarimetric radar data; J. Appl. Meteor. 42 1679-1690.

Klimowski B A and Bunkers M J 2002 Comments on satellite observations of a supercell thunderstorm on 24 July 2000 made during the GOES-11 Science Test; Wea. Forecasting 17 1111-1117.

MacKeen P L, Brooks H E and Elmore K L 1999 Radar reflectivity-derived thunderstorm parameters applied to storm longevity forecasting; Wea. Forecasting 14 289-295.

Marwitz J D 1972a The structure and motion of severe hailstorms. Part I: Supercell storms; J. Appl. Meteor. 11 166-179.

Marwitz J D 1972b The structure and motion of severe hailstorms. Part II: Multicell storms; J. Appl. Meteor. 11 $180-188$

Marwitz J D 1972c The structure and motion of severe hailstorms. Part III: Severely sheared storms; J. Appl. Meteor. 11 189-201.

Mukhopadhyay P, Singh H A K and Singh S S 2005 Two severe Nor'westers in April 2003 over Kolkata, India using Doppler radar observations and satellite imageries; Weather 60 343-353.

Mull S and Rao Y P 1950 Dynamics of thunderstorms: Part I; Ind. J. Meteor. Geophys. 1 116-136.

Mull S and Rao Y P 1950 Dynamics of thunderstorms: Part II; Ind. J. Meteor. Geophys. 1 291-297.

Rai Sircar N C 1957 On the forecasting of Nor'westers in Gangetic West Bengal; Ind. J. Meteor. Geophys. 8 21-32.

Rao D V and Boothalingam P N 1957 On forecasting the time of incidence of Nor'westers at Calcutta; Ind. J. Meteor. Geophys. 8 61-66.

Ricketts H, Russell A and Norton E 2007 Meeting report thunderstorms; Weather 62 107-108.

Sohoni V V 1928 Thunderstorms of Calcutta, 1900-1926. Ind. Met. Dept. Sci. Notes I(3) 25-36.

Short D A, Sardonia J E, Lambert W C and Wheeler M M 2004 Nowcasting thunderstorm Anvil Clouds over Kennedy Space Center and Cape Canaveral Air Force Station; Wea. Forecasting 19 706-713.

Wakimoto R M 1982 The life cycle of thunderstorm gust fronts as viewed with Doppler radar and rawinsonde data; Mon. Wea. Rev. 110 1060-1082.

Weaver J F, Knaff J A, Bikos D, Wade G S and Daniels J M 2002 Satellite observations of a supercell thunderstorm on 24 July 2000 made during the GOES-11 science test; Wea. Forecasting 17 124-138.

Weaver J F and Lindsey D 2004 Some frequently overlooked severe thunderstorm characteristics observed on GOES imagery: A topic for future research; Mon. Wea. Rev. 132 1529-1533.

Weckwerth T M 2000 The effect of small-scale moisture variability on thunderstorm initiation; Mon. Wea. Rev. 128 4017-4030. 